\title{
Virginia Bicycle Data: Automobile and Bicycle Crash Safety Analysis and Virginia Attitudinal Safety Survey
}

\author{
A Thesis \\ Presented to \\ the faculty of the School of Engineering and Applied Science \\ University of Virginia \\ in partial fulfillment \\ of the requirements for the degree \\ Master of Science \\ by \\ Erin M Robartes \\ August 2017
}




\title{
APPROVAL SHEET
}

\author{
This Thesis \\ Is submitted in partial fulfillment of the requirements \\ for the degree of \\ Master of Science
}

Author Signature: Erin Rokat

This thesis has been read and approved by the examining committee:

Advisor: Donna Chen

Committee Member: Brian Smith

Committee Member: Brian Park

Committee Member: Michael Fontaine

Committee Member: Peter Ohlms

Accepted for the School of Engineering and Applied Science:

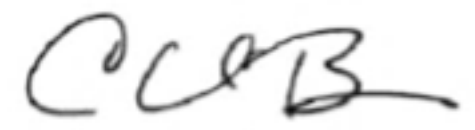

Craig H. Benson, School of Engineering and Applied Science

August 2017 


\section{ABSTRACT}

The first portion of this thesis examines bicyclist, automobile driver, vehicle, environmental, and roadway characteristics that influence cyclist injury severity in order to determine which factors should be addressed to mitigate the worst bicyclist injuries. An ordered probit model is used to examine single bicyclesingle vehicle crashes from Virginia police crash report data from 2010 to 2014 . Five injury severity levels are considered: fatalities, severe injuries, minor or possible injuries, no apparent injuries, and no injury. The results of this study most notably found automobile driver intoxication to increase the probability of a cyclist fatality six-fold and double the risk of a severe injury, while bicyclist intoxication increases the probability of a fatality by $36.7 \%$ and doubles the probability of severe injury. Additionally, bicycle and automobile speeds, obscured automobile driver vision, specific vehicle body types (SUV, truck, and van), vertical roadway grades and horizontal curves elevate the probability of more severe bicyclist injuries. Model results encourage consideration of methods to reduce the impact of biking and driving while intoxicated such as analysis of bicycling under the influence laws, education of drunk driving impacts on bicyclists, and separation of vehicles and bicycles on the road. Additionally, the results encourage consideration of methods to improve visibility of bicyclists and expectation of their presence on the road.

After the conclusion of the Virginia police crash data analysis, an analysis of nationwide bicycling under the influence laws and bicycle crashes was undertaken. Ultimately the nationwide data on bicycle fatality crashes from the fatality analysis reporting system proved to be insufficient to answer the questions posed, whether bicycling under the influence laws improve safety. As another outcome of the Virginia police crash data analysis a survey deployment project was completed, described in part two of this thesis. The purpose of this survey in part is to capture elements of bicycle data that were found to be lacking in the police crash reports. The survey development and analysis enhances the quality and quantity of available bicycle data in Virginia through the design and distribution of a survey throughout the state. The survey is particularly intended to capture bicyclist attitudes and perceptions of safety as well as bicycle crash data, as bicycle crashes are heavily under reported in police reported crash databases. The data is then analyzed using various statistical modeling techniques. The results of this survey most notably show very high levels of underreporting of bicycle crashes, only $12 \%$ of the crashes recorded in this survey were reported by the police. Additionally, the results of this work show that lack of knowledge concerning bicycle laws was associated with lower levels of confidence towards biking. Education could have an impact not only towards helping people be safer bicyclists on the road, but to bring more people on the road to start with. Additionally, it was found that when bicyclists act appropriately at traffic signals, by stopping they are less likely to be involved in car crashes. This could also be influenced by better education on how bicyclists are required to act on the road.

Keywords: Bicycles, Safety, Crash Analysis, Ordered Probit Model, Survey, Virginia 


\section{TABLE OF CONTENTS}

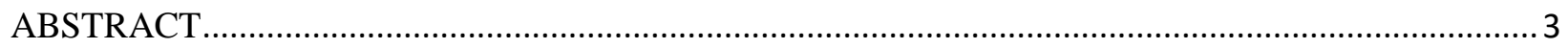

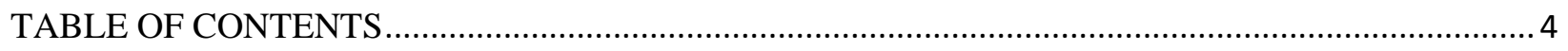

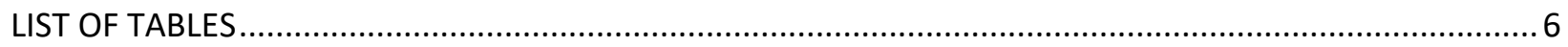

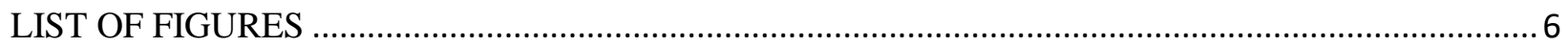

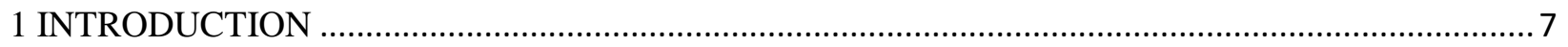

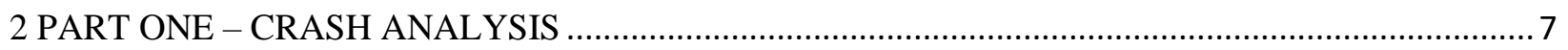

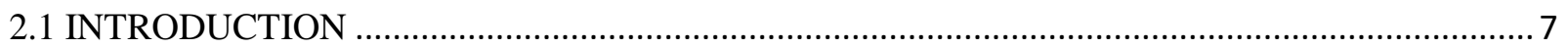

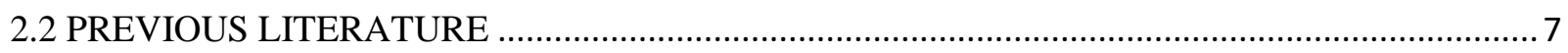

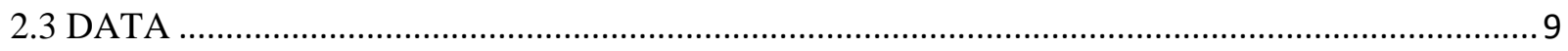

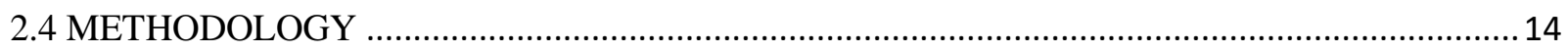

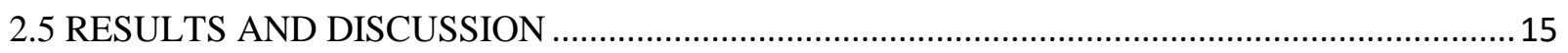

2.5.1 Bicyclist Characteristics .............................................................................................

2.5.2 Automobile Driver Characteristics ................................................................................ 18

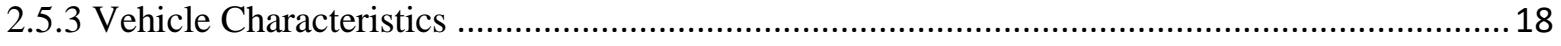

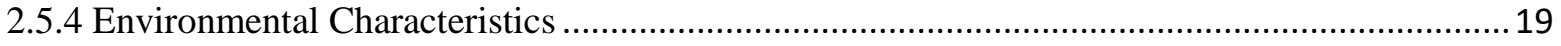

2.5.5 Roadway Characteristics.................................................................................................. 19

2.6 CONCLUSIONS AND LIMITATIONS …………………………………………………20

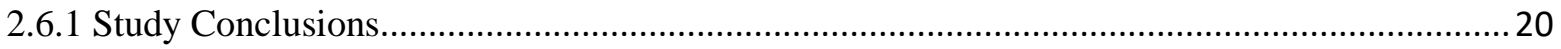

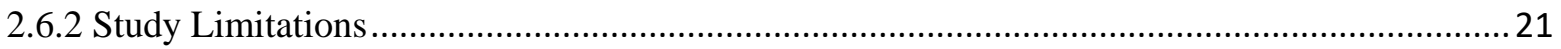

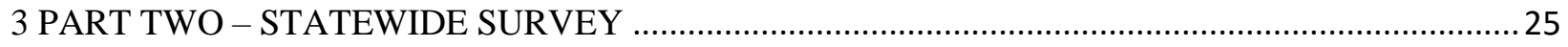

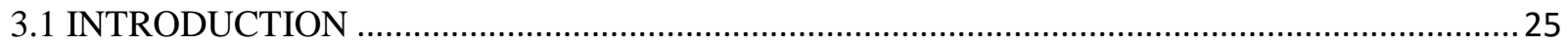

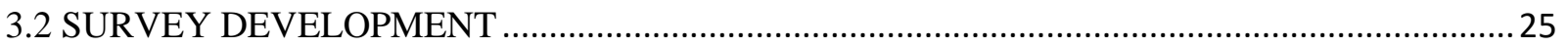

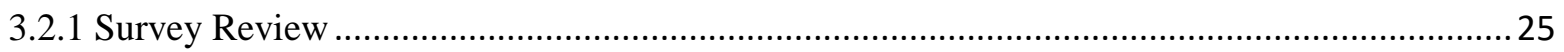

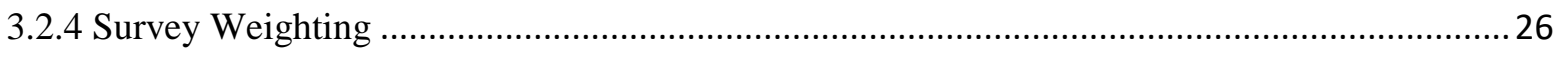

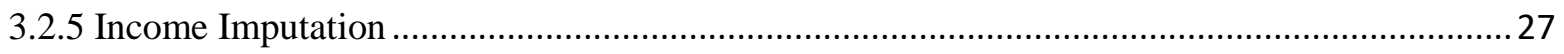

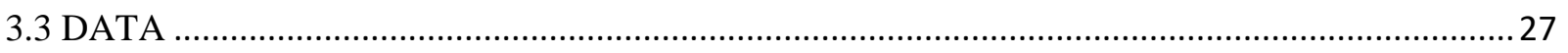

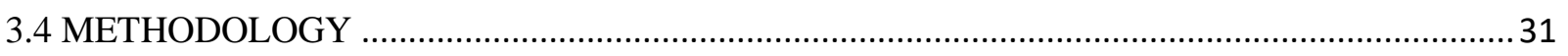

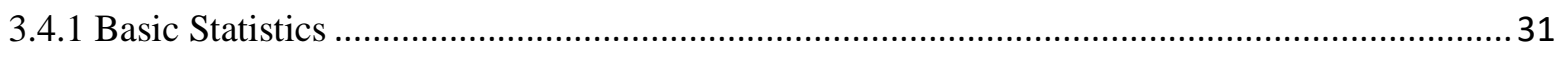

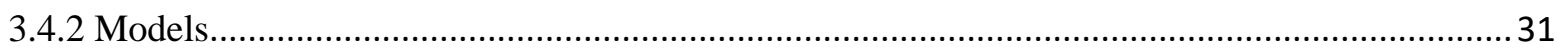

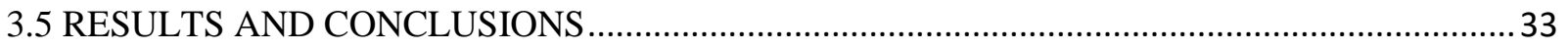

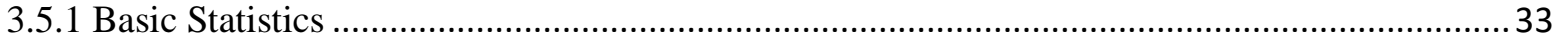

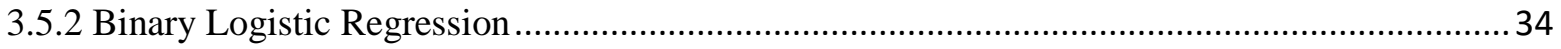




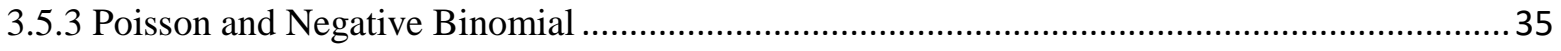

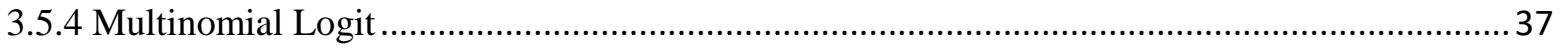

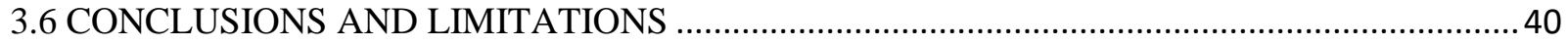

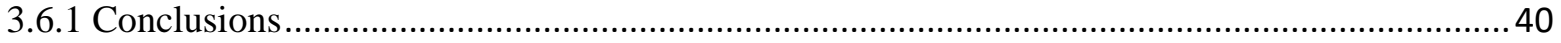

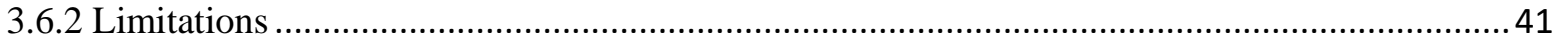

4 CONCLUSION

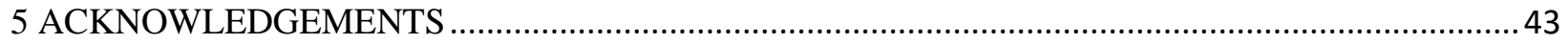

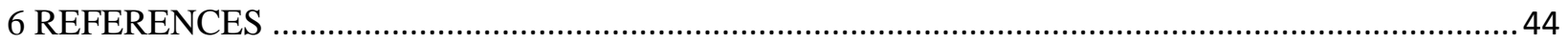

7 APPENDIX

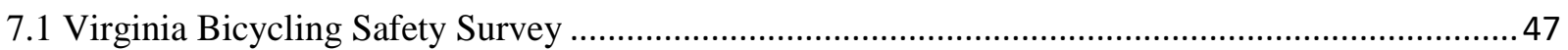




\section{LIST OF TABLES}

TABLE 1 Bicyclist and Automobile Driver Descriptive Statistics

TABLE 2 Vehicle, Roadway, Environment, and Location Descriptive Statistics................................... 12

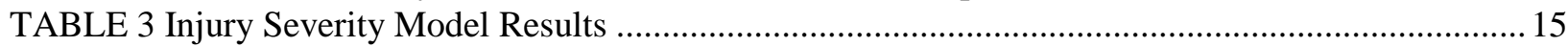

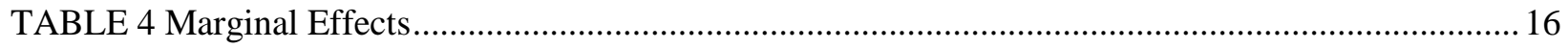

TABLE 5 Descriptive characteristics of survey questions with multiple responses.................................22

TABLE 6 Descriptive statistics for survey questions with binary responses. ......................................... 30

TABLE 7 Model results for binary logistic regression of knowledge of helmet laws.Error! Bookmark not defined.

TABLE 8 Model results for binary logistic regression for knowledge of Virginia headlight laws.....Error! Bookmark not defined.

TABLE 9 Model results of binary logistic regression model of knowledge of bicycling under the influence laws Error! Bookmark not defined.

TABLE 10 Model results for binomial logistic regression of knowledge of Virginia's stop sign and traffic

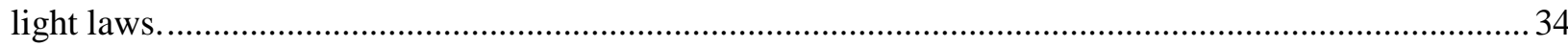

TABLE 11 Model results from poisson count model of number of bicycle crashes a person is involved in.

TABLE 12 Model results from negative binomial count model of number of bicycle crashes a person is

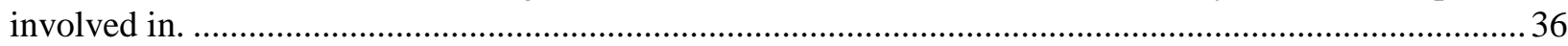

TABLE 13 Parameter estimates for helmet use multinomial logit model .............................................. 38

Table 14 Parameter Estimates for multinomial logit model of bicycling attitude. .................................. 39

\section{LIST OF FIGURES}

FIGURE 1 Map of Virginia automobile-bicycle crashes from 2010 to 2014 .......................................... 10

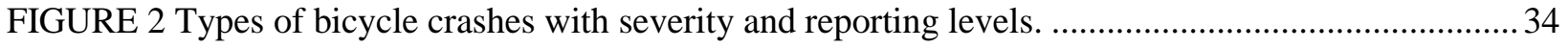

FIGURE 3 Histogram of respondent number of crashes. ..................................................................... 35 


\section{INTRODUCTION}

Bicycling is a healthy, inexpensive, and environmentally friendly activity for recreation, travel, or commuting. Biking can promote the health of individuals (Andersen, Schnohr, Schroll, \& Hein, 2000; Bassett, Pucher, Buehler, Thompson, \& Crouter, 2008) reduce carbon emissions and encourage a more livable society (Garrick and Marshall, 2011). Building a bike friendly city where road networks, and infrastructure can be used by non-motorized vehicles has been shown to improve safety conditions for all road users (Garrick and Marshall, 2011). For the individual bicyclist, the benefits of bicycling outweigh the risks compared to the benefits and risks of driving in a motor vehicle (De Hartog, Boogaard, Nijland, \& Hoek, 2010). Encouraging non-motorized travel can have benefits on the bicycling participants as well as the environment we live in. Within the state of Virginia, bicycling conditions vary across cities and counties. The purpose of this research is to better understand the state of bicycling safety conditions in Virginia and reveal factors that negatively and positively impact safety using two approaches. The first method used to improve understanding of bicycling safety in Virginia is by analyzing the most comprehensive dataset available of bicycle crashes, police reported crashes acquired through the Virginia Department of Motor Vehicles. The second method used is the design, distribution, and analysis of a bicycling safety and attitude survey which attempts to fill gaps in the available bike data in Virginia. This thesis is organized into two sections, part one and part two that detail the research process associated with each of these projects.

\section{PART ONE - CRASH ANALYSIS}

\subsection{INTRODUCTION}

Over the past two decades, fatality rates associated with automobile crashes have declined nationally in the United States. During this same time, the absolute number of bicyclist fatalities has also declined. However, bicyclist fatalities as a percentage of total transportation related deaths (automobile, motorcycle, pedestrian, and cyclist) have increased, representing a slower decline in mitigating bicyclist fatalities as compared to other transportation modes (Fatality, 2014). Meanwhile, the rate of bicycling in the United States is on the rise. Nationwide modal share of bike commuters rose $67 \%$ between 2005 and 2015, an increase of approximately 357,600 bike commuters (US Census, 2015). This percentage increase is even higher in Virginia, where bike commuters increased $128 \%$ in the same time period, by approximately 9,260 commuters (US Census 2015). As cities, counties, and departments of transportation invest more into bicycle infrastructure and bicycling rates continue to grow, it must be understood what can be done to minimize the crash risk of vulnerable bicyclists. Between 2010 and 2014, 3679 crashes between bicyclists and automobiles were reported in Virginia. Forty-nine of those crashes resulted in a fatality. These statistics highlight the need to understand the causes behind the most severe and deadly bicycle and automobile collisions in order to mitigate dangerous crashes in the future. This research analyzes Virginia bicycle and automobile crash data to identify the factors which contribute to injury severity of bicyclists in bicycle-automobile crashes.

\subsection{PREVIOUS LITERATURE}

Previous studies have identified many possible factors contributing to crashes between bicycles and automobiles, including infrastructure, environmental, and temporal factors, as well as driver, vehicle, and roadway characteristics. Reynolds et al. (2009) reviewed 23 papers that examined the effect of transportation infrastructure on bicyclist crashes and injury, concluding that bicycle-specific facilities such as bike routes, bike lanes, and off-road bike paths reduce cyclist crashes and injury. Bicycle-specific facilities are in contrast with mixed-traffic facilities where bikes share motor vehicle lanes or travel on sidewalks. Additionally, bicyclist safety was shown to improve with street lighting, paved surfaces, and low angle grades (Reynolds et al., 2009). 
In addition to transportation facility and environmental factors, human factors also contribute to bicycle and automobile crashes. Lack of attention from bicyclists and automobile drivers about their surroundings, as well as unclear expectations about the behavior of other cars and bikes on the road, leads to bicycle and automobile crashes. For example, Rasanen and Summala (1997) conclude that the most common bicycle-car collision results when the driver looks left for oncoming vehicles when they should also be looking right for cyclists. This lack of driver expectation about where bicyclists will be and how they will behave increases the occurrence of bicycle-automobile crashes.

Other studies have focused on factors that specifically affect injury severity in bicycle and automobile crashes. Identifying factors that contribute to the most severe bicyclist injuries can motivate policy and infrastructure changes to prevent the most debilitating of crashes. Previous studies have shown that temporal and environmental characteristics can influence injury severity. By cycling at night, the likelihood of a severe bicyclist crash increases (Eluru et al., 2008; Rodgers, 1995). Eluru et al. (2008) found that riding between midnight and 6am increases the probability of a fatal crash by almost five-fold compared to daytime $(6 \mathrm{am}$ to $6 \mathrm{pm})$ riding. Night time riding is particularly dangerous in areas without streetlights (Yan, Huang, Abdel-Aty, \& Wu, 2011; Kim, Kim, Ulfarsson, Porrell, 2007; Klop and Khattak, 1999). Kim et al. (2007) identified cycling at night without streetlights as a crash injury risk, increasing the probability of a fatal injury by $110.9 \%$ compared to crashes occurring in daytime or in areas with streetlights. Similarly, fog leads to a reduction in visibility and has been shown to be a risk factor for increased injury severity (Klop and Khattak, 1999). More broadly, inclement weather has been identified as a factor in doubling the risk of a fatal cyclist injury (Kim et al., 2007).

Cyclist characteristics, such as age, gender, and alcohol consumption, are also risk factors for increased cyclist injury severity. Numerous studies have cited advanced age of the bicyclist as a risk factor (Yan et al., 2011; 10, Eluru et al., 2008). Kim et al. (2007) specifically describe cyclists over the age of 55 as a factor that could double the risk of a fatality. Similarly, Rodgers (1995) concludes that cyclists older than 44 are at a greater risk for a fatality and Eluru et al. (2008) found that cyclists over age 60 are more than four times more likely to be fatally injured compared to bicyclists younger than 60. Rodgers (1995) also found that males have a five times greater risk of being killed in a bike crash compared to females, when adjusted for exposure. Alcohol consumption has also been shown to increase severe injuries. Sethi et al. (2016) found that alcohol use in urban bicyclists was inversely correlated with helmet use and associated with more severe injuries and greater mortalities. Andersson and Bunketorp (2002) found that intoxicated cyclists less often wore helmets and were at a greater risk of head and face injuries. Specifically, Moore Schneider, Savolainen, \& Farzaneh (2011) found that when the automobile driver was under the influence of alcohol, the likelihood of a severe injury increased by $82.2 \%$ if the crash occurred at an intersection and $150.1 \%$ at a non-intersection location. Kim et al. (2007) also found the probability of a fatal injury to more than double if either the cyclist or the driver in a crash were intoxicated.

Automobile characteristics such as speed of the automobile, type of automobile, and angle at which the automobile collided with the bicycle have also been shown to affect injury severity. In several studies, high vehicle speed at the time of collision increased likelihood of a severe injury. The exact speed which constitutes a high speed is not consistent in all studies, with most studies simply concluding higher speeds lead to more dangerous crashes (Eluru et al., 2008; Yan et al., 2011; Moore et al., 2011). Kim et al. (2007) specifically identify speeds above $30 \mathrm{mph}$ to double the probability for a fatality, and that speeds above 50 mph increase the risk of fatality by 16-fold compared to speeds less than $20 \mathrm{mph}$. Eluru et al. (2008) found that speeds above $50 \mathrm{mph}$ increase fatality risks by $470.8 \%$ compared to speeds below $25 \mathrm{mph}$. Additionally, if the vehicle involved in the collision is a heavy-duty vehicle, injury severity risk also increases (Yan et al., 2011; Kim et al., 2007, Moore et al., 2011). Kim et al. (2007) find that in bicycle collisions with heavy trucks, the probability of a fatality increases by $390.9 \%$ and the probability of an incapacitating injury increase by $101.8 \%$. Furthermore, head-on (Yan et al., 2011; Kim et al., 2007) and angle collisions (Yan et al., 2011; Moore et al., 2011) were shown to increase injury severity. Kim et al. (2007) found that head-on collisions double the probability of a fatal injury.

Lastly, roadway characteristics have also been shown to affect injury severity levels. Kim et al. (2007) found that divided roads increase non-incapacitating injuries by 13.5\%. Yan et al. (2011) found that 
fewer bicyclists rode against traffic when there was a median, which was previously hypothesized by Kim et al. (2007) as a reason for reduced injury severity on divided roads. Klop and Khattak (1999) discuss grades on straight and curved roads as being detrimental to bike safety. Additionally, Moore et al. (2011) found horizontal curves with grades in intersections and horizontal and vertical curves at non-intersection locations to increase injury severity. Eluru et al. (2008) also found that crashes at signalized intersections were less severe than at other locations, reducing the probability of a fatal crash by almost $90 \%$. This research aims to corroborate previous findings about factors that increase injury severity and uncover new findings using a Virginia-based crash dataset.

\subsection{DATA}

The data analyzed come from Virginia police crash reports collected between 2010 and 2014 across the entire state. The Virginia Department of Motor Vehicles (VA DMV) provided information for 3679 reported crashes involving a bicyclist. The data include characteristics about the crash, roadway, environment, vehicles (bikes and automobiles), and drivers (cyclists and automobile drivers).

The characteristics defined in the dataset are studied in this research for their effect on bicycle injury severity and therefore these injury severity outcomes are defined explicitly. The Virginia State Crash Report Manual categorizes injury outcomes as fatal, severe injury, minor/possible injury, no apparent injury, and no injury. The bicyclist injury category is determined at the discretion of the police officer (given provided manual guidelines) at the scene of the crash. Fatalities include all injuries that result in death within 30 days of the crash. Severe injuries include severe lacerations, broken or distorted limbs, crush injuries, significant burns, unconsciousness or paralysis. Minor or possible injuries include visible injuries such as bruises, abrasions, swelling or limping. No apparent injury is cited when there is no visible injury but the person complains of pain or becomes briefly unconscious. No injury is recorded when by the officer's best judgement, no injury has occurred (Virginia DMV, 2015). This method of injury severity collection is open to subjectivity on the part of the police officer, and has been found to produce some inaccurate injury reporting as discussed by Farmer (2003). This type of data assessment is discussed in more depth in the section on limitations of the study.

While all the crashes in the VA DMV dataset involve bicyclists, they do not all involve the same number of bicyclists and automobiles. For the purpose of this research (due to limited sample size of other crash types), only crashes between one automobile and one bicycle are included. 3545 (96.4\%) of the original VA DMV dataset are single automobile and bike crashes. The removed crash observations include 46 single bicycle crashes (where no automobile was identified), 37 multiple bike crashes (32 involving two bikes and 5 involving three or more bikes), and 51 crashes involving multiple automobiles. The purpose of this limitation is to focus directly on the dynamic between a single automobile and a single bicycle. Including other automobiles or bicycles confounds the physics and interpretation of the crash, where the main event may be the automobiles hitting each other, or the bicycles crashing into each other instead of the interaction between the car and bike. Furthermore, this study does not assess other common types of crashes, such as single bicycle crashes where no automobile is involved. Due to the automobile-focused nature of the police crash reports (which are most commonly used to capture car crashes and do not contain all safety information relevant to bikes), single bicycle crashes (with no automobile involved) are not data that are readily captured in this statewide dataset.

These 3545 crashes have been plotted using latitude and longitude coordinates provided in the dataset. Figure 1 shows a map of the crashes in Virginia to help understand the visual spread of the data. Property damage only (PDO), injury, and fatal crashes are shown in green, yellow, and red respectively to provide information about the injury severity of the bicyclist in the crash. 


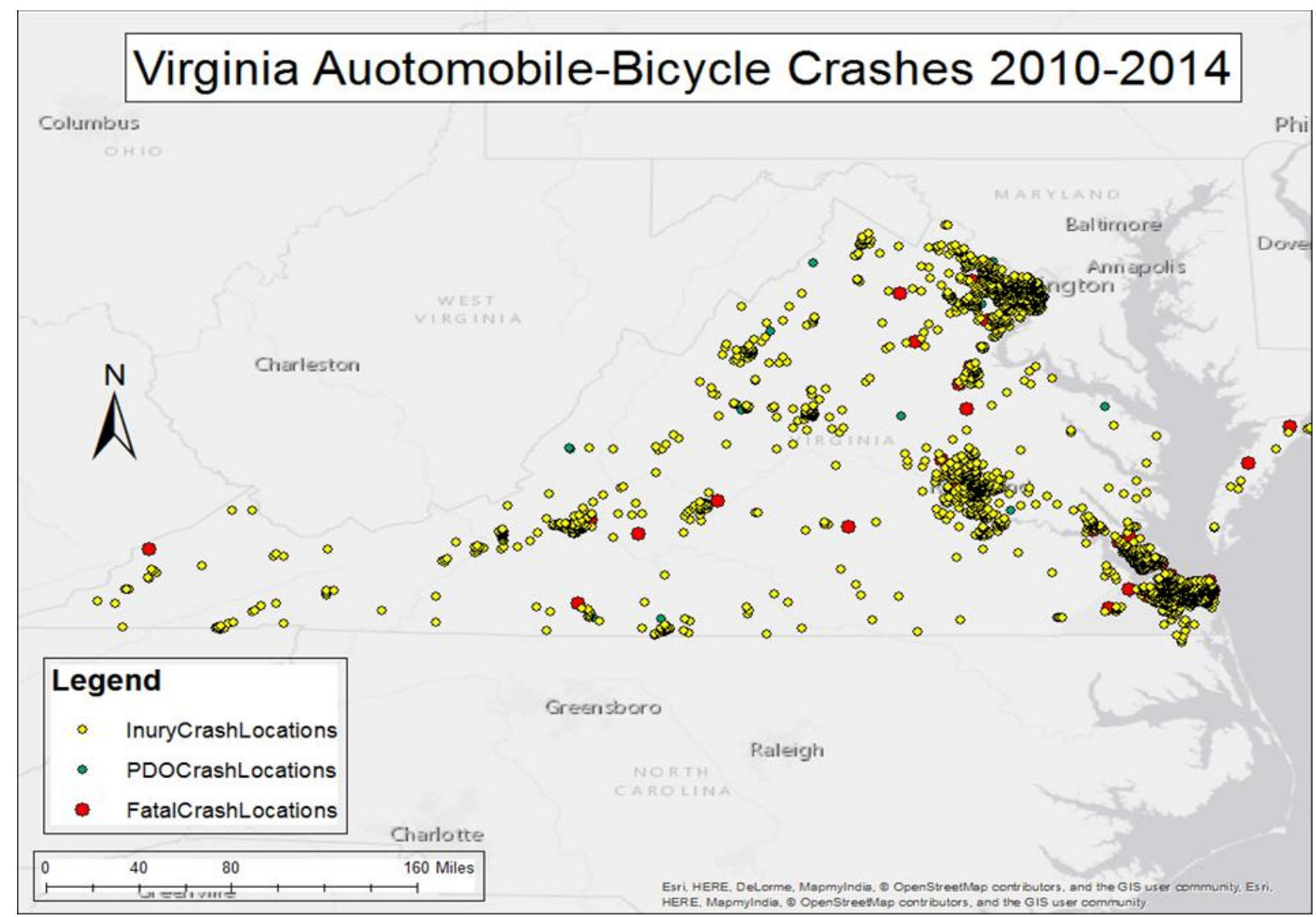

FIGURE 1 Map of Virginia automobile-bicycle crashes from 2010 to 2014

Within the 3545-crash dataset, some key variables have missing data. The final analysis dataset (with all missing data observations removed) contains 2435 crashes, and its descriptive statistics are shown in Table 1 and Table 2. Compared to the original complete set of crashes in the database, the analysis data $(\mathrm{N}=2435)$ had proportionally more fatal bicyclist crashes (just over 50\%) removed compared to other injury severities, which had 28 to $34 \%$ of observations removed due to missing data. To determine the source of this discrepancy, variables with missing data were examined, and it was found that the percentage of missing data for driver drinking is lower among fatal crashes (8.9\% compared to $17 \%$ ), but is significantly higher for bicyclist drinking (37.8\% compared to $10.1 \%$ ) and bicyclist speed (31.1\% compared to $13.9 \%)$, and slightly higher for driver speed (11.1\% compared to $6.8 \%$ ). These high levels of missing data are likely a result of the decreased likelihood that the officer has knowledge about the bicyclist's level of alcohol or speed when a fatality has occurred.

Tables 1 and 2 give descriptive statistics for variables considered in this study. Variable frequencies are given for each injury severity level and those frequencies are summed in the total column. Percentages under injury severity levels signify the percentage of cases in that level out of the total cases for that variable. Percentages in the total column indicate the percentage of cases in each variable out of the total 2435 cases in the dataset.

TABLE 1 Bicyclist and Automobile Driver Descriptive Statistics

\begin{tabular}{|l|l|l|l|l|l|l|}
\hline Variables & $\begin{array}{l}\text { Fatal } \\
\text { Injury }\end{array}$ & $\begin{array}{l}\text { Severe } \\
\text { Injury }\end{array}$ & $\begin{array}{l}\text { Minor/ } \\
\text { Possible } \\
\text { Injury }\end{array}$ & $\begin{array}{l}\text { No } \\
\text { Apparent } \\
\text { Injury }\end{array}$ & $\begin{array}{l}\text { No } \\
\text { Injury }\end{array}$ & Total** \\
\hline
\end{tabular}




\begin{tabular}{|c|c|c|c|c|c|c|c|}
\hline \multicolumn{8}{|c|}{ Bicyclist Characteristics } \\
\hline Injury Type & & $\begin{array}{l}20 \\
(1 \%)\end{array}$ & $\begin{array}{l}557 \\
(23 \%) \\
\end{array}$ & $\begin{array}{l}1357 \\
(56 \%)\end{array}$ & $\begin{array}{l}437 \\
(18 \%)\end{array}$ & $\begin{array}{l}64 \\
(3 \%) \\
\end{array}$ & $\begin{array}{l}2435 \\
(100 \%) \\
\end{array}$ \\
\hline $\begin{array}{l}\text { Continuous } \\
\text { Variable* }\end{array}$ & $\begin{array}{l}\text { Bicycle Speed } \\
\text { Before Crash in } \\
\mathrm{mph}(\mathrm{km} / \mathrm{h})\end{array}$ & $\begin{array}{l}6.90 \\
(11.1)\end{array}$ & $\begin{array}{l}7.97 \\
(12.8)\end{array}$ & $\begin{array}{l}7.74 \\
(12.5)\end{array}$ & $\begin{array}{l}5.70 \\
(9.17)\end{array}$ & $\begin{array}{l}10.3 \\
(16.6)\end{array}$ & $7.49(12.1)$ \\
\hline \multirow[t]{2}{*}{$\begin{array}{l}\text { Vision } \\
\text { Obscured }\end{array}$} & No & $\begin{array}{l}18 \\
(1 \%)\end{array}$ & $\begin{array}{l}485 \\
(22 \%)\end{array}$ & $\begin{array}{l}1230 \\
(56 \%)\end{array}$ & $\begin{array}{l}402 \\
(18 \%)\end{array}$ & $\begin{array}{l}54 \\
(2 \%)\end{array}$ & $2189(90 \%)$ \\
\hline & Yes & $2(1 \%)$ & $72(29 \%)$ & $127(52 \%)$ & $35(14 \%)$ & $\begin{array}{l}10 \\
(4 \%)\end{array}$ & $246(10 \%)$ \\
\hline \multirow[t]{2}{*}{ Distracted } & No Distraction & $\begin{array}{l}17 \\
(1 \%) \\
\end{array}$ & $\begin{array}{l}491 \\
(23 \%)\end{array}$ & $\begin{array}{l}1204 \\
(56 \%)\end{array}$ & $\begin{array}{l}380 \\
(18 \%) \\
\end{array}$ & $\begin{array}{l}54 \\
(3 \%) \\
\end{array}$ & $2146(88 \%)$ \\
\hline & Distraction & $3(1 \%)$ & $66(23 \%)$ & $153(53 \%)$ & $57(20 \%)$ & $\begin{array}{l}10 \\
(3 \%)\end{array}$ & $289(12 \%)$ \\
\hline \multirow[t]{2}{*}{ Helmet } & No Helmet & $4(1 \%)$ & $\begin{array}{l}167 \\
(26 \%)\end{array}$ & $333(51 \%)$ & $\begin{array}{l}139 \\
(21 \%)\end{array}$ & $\begin{array}{l}10 \\
(2 \%)\end{array}$ & $653(27 \%)$ \\
\hline & Helmet & $7(1 \%)$ & $\begin{array}{l}162 \\
(23 \%)\end{array}$ & $422(60 \%)$ & $89(13 \%)$ & $\begin{array}{l}23 \\
(3 \%)\end{array}$ & $703(29 \%)$ \\
\hline \multirow[t]{2}{*}{ Drug Use } & No & $\begin{array}{l}12 \\
(1 \%)\end{array}$ & $\begin{array}{l}437 \\
(23 \%)\end{array}$ & $\begin{array}{l}1086 \\
(57 \%)\end{array}$ & $\begin{array}{l}334 \\
(17 \%)\end{array}$ & $\begin{array}{l}53 \\
(3 \%) \\
\end{array}$ & $1922(79 \%)$ \\
\hline & Yes & $0(0 \%)$ & $3(50 \%)$ & $2(33 \%)$ & $1(17 \%)$ & $0(0 \%)$ & $6(0 \%)$ \\
\hline \multirow[t]{2}{*}{ Drinking } & No & $\begin{array}{l}16 \\
(1 \%)\end{array}$ & $\begin{array}{l}513 \\
(22 \%) \\
\end{array}$ & $\begin{array}{l}1302 \\
(56 \%)\end{array}$ & $\begin{array}{l}416 \\
(18 \%) \\
\end{array}$ & $\begin{array}{l}60 \\
(3 \%)\end{array}$ & $2307(95 \%)$ \\
\hline & Yes & $4(3 \%)$ & $44(34 \%)$ & $55(43 \%)$ & $21(16 \%)$ & $4(3 \%)$ & $128(5 \%)$ \\
\hline \multirow[t]{2}{*}{ Gender } & Male & $\begin{array}{l}14 \\
(1 \%) \\
\end{array}$ & $\begin{array}{l}443 \\
(24 \%) \\
\end{array}$ & $\begin{array}{l}1026 \\
(55 \%) \\
\end{array}$ & $\begin{array}{l}337 \\
(18 \%) \\
\end{array}$ & $\begin{array}{l}54 \\
(3 \%) \\
\end{array}$ & $1874(77 \%)$ \\
\hline & Female & $3(1 \%)$ & $87(19 \%)$ & $271(61 \%)$ & $79(18 \%)$ & $7(2 \%)$ & $447(18 \%)$ \\
\hline \multirow[t]{2}{*}{$\begin{array}{l}\text { Vehicle } \\
\text { Condition }\end{array}$} & Not Defective & $\begin{array}{l}19 \\
(1 \%) \\
\end{array}$ & $\begin{array}{l}521 \\
(23 \%) \\
\end{array}$ & $\begin{array}{l}1286 \\
(56 \%) \\
\end{array}$ & $\begin{array}{l}411 \\
(18 \%) \\
\end{array}$ & $\begin{array}{l}57 \\
(2 \%) \\
\end{array}$ & $2294(94 \%)$ \\
\hline & Defective & $1(1 \%)$ & $36(26 \%)$ & $71(50 \%)$ & $26(18 \%)$ & $7(5 \%)$ & $141(6 \%)$ \\
\hline \multicolumn{8}{|c|}{ Automobile Driver Characteristics } \\
\hline \multirow[t]{4}{*}{ Injury Type } & Severe Injury & $0(0 \%)$ & $7(78 \%)$ & $1(11 \%)$ & $1(11 \%)$ & $0(0 \%)$ & $9(0 \%)$ \\
\hline & Minor/Possible & $1(7 \%)$ & $6(43 \%)$ & $5(36 \%)$ & $0(0 \%)$ & $\begin{array}{l}2 \\
(14 \%)\end{array}$ & $14(1 \%)$ \\
\hline & No Apparent & $2(1 \%)$ & $32(17 \%)$ & $140(75 \%)$ & $11(6 \%)$ & $1(1 \%)$ & $186(8 \%)$ \\
\hline & No Injury & $\begin{array}{l}17 \\
(1 \%)\end{array}$ & $\begin{array}{l}512 \\
(23 \%)\end{array}$ & $\begin{array}{l}1207 \\
(54 \%)\end{array}$ & $\begin{array}{l}424 \\
(19 \%)\end{array}$ & $\begin{array}{l}61 \\
(3 \%)\end{array}$ & $2221(91 \%)$ \\
\hline \multirow[t]{2}{*}{$\begin{array}{l}\text { Vision } \\
\text { Obscured }\end{array}$} & Not Obscured & $\begin{array}{l}14 \\
(1 \%)\end{array}$ & $\begin{array}{l}450 \\
(22 \%)\end{array}$ & $\begin{array}{l}1121 \\
(56 \%)\end{array}$ & $\begin{array}{l}375 \\
(19 \%) \\
\end{array}$ & $\begin{array}{l}56 \\
(3 \%) \\
\end{array}$ & $2016(83 \%)$ \\
\hline & Obscured & $6(1 \%)$ & $\begin{array}{l}107 \\
(26 \%)\end{array}$ & $236(56 \%)$ & $62(15 \%)$ & $8(2 \%)$ & $419(17 \%)$ \\
\hline \multirow[t]{2}{*}{ Distracted } & Not Distracted & $\begin{array}{l}18 \\
(1 \%) \\
\end{array}$ & $\begin{array}{l}501 \\
(23 \%)\end{array}$ & $\begin{array}{l}1198 \\
(55 \%) \\
\end{array}$ & $\begin{array}{l}381 \\
(18 \%)\end{array}$ & $\begin{array}{l}62 \\
(3 \%) \\
\end{array}$ & $2160(89 \%)$ \\
\hline & Distracted & $2(1 \%)$ & $56(20 \%)$ & $159(58 \%)$ & $56(20 \%)$ & $2(1 \%)$ & $275(11 \%)$ \\
\hline \multirow[t]{2}{*}{ Drug Use } & No & $\begin{array}{l}15 \\
(1 \%) \\
\end{array}$ & $\begin{array}{l}451 \\
(23 \%) \\
\end{array}$ & $\begin{array}{l}1107 \\
(56 \%)\end{array}$ & $\begin{array}{l}339 \\
(17 \%) \\
\end{array}$ & $\begin{array}{l}50 \\
(3 \%) \\
\end{array}$ & $1962(81 \%)$ \\
\hline & Yes & $0(0 \%)$ & $1(20 \%)$ & $4(80 \%)$ & $0(0 \%)$ & $0(0 \%)$ & $5(0 \%)$ \\
\hline
\end{tabular}




\begin{tabular}{|l|l|l|l|l|l|l|l|}
\hline Drinking & No & $\begin{array}{l}19 \\
(1 \%)\end{array}$ & $\begin{array}{l}539 \\
(23 \%)\end{array}$ & $\begin{array}{l}1348 \\
(56 \%)\end{array}$ & $\begin{array}{l}433 \\
(18 \%)\end{array}$ & $\begin{array}{l}64 \\
(3 \%)\end{array}$ & $2403(99 \%)$ \\
\hline & Yes & $1(3 \%)$ & $18(56 \%)$ & $9(28 \%)$ & $4(13 \%)$ & $0(0 \%)$ & $32(1 \%)$ \\
\hline Gender & Male & $\begin{array}{l}15 \\
(1 \%)\end{array}$ & $\begin{array}{l}315 \\
(24 \%)\end{array}$ & $728(55 \%)$ & $\begin{array}{l}229 \\
(17 \%)\end{array}$ & $\begin{array}{l}34 \\
(3 \%)\end{array}$ & $1321(54 \%)$ \\
\hline & Female & $5(0 \%)$ & $\begin{array}{l}237 \\
(22 \%)\end{array}$ & $620(57 \%)$ & $\begin{array}{l}203 \\
(19 \%)\end{array}$ & $\begin{array}{l}30 \\
(3 \%)\end{array}$ & $1095(45 \%)$ \\
\hline
\end{tabular}

*Continuous variables are presented with means in $\mathrm{mph}$ and $\mathrm{km} / \mathrm{h}$ in place of frequencies and percentages **Percentages in totals column for variables not used in the model may not sum to $100 \%$ due to missing data

Among bicyclist and automobile driver statistics, some notable trends concern gender, drinking, and helmet use. Males comprise $77 \%$ of bicyclists in crashes, compared to $18 \%$ of females. Distribution of gender among automobile drivers involved in crashes is more evenly split with males (54\%) still topping females (45\%) in total crashes. In fatal crashes, the male to female ratio of bicyclists is 14 to 3 which is similar to the total gender ratio. However, for automobile drivers the male to female ratio in fatal crashes is 15 to 5, showing males overrepresented as drivers in fatal crashes.

Concerning helmet use, a variable not included in the final model, the helmet use variable in the dataset was consistently incorrectly reported, resulting in very high numbers of missing data. Helmet use fell under a broader category entitled "Safety Equipment Used" that was used for all drivers. Only two of the nine options in this category are intended to describe bicyclist safety equipment (Helmet Used and No Restraint Used). A third category "Not Applicable" was unfortunately used to describe about one third of bicyclists in this dataset despite the fact that The Virginia State Crash Report Manual explicitly states "Not Applicable" should not be used to describe a bicyclist not wearing a helmet (Virginia DMV, 2015). Because of the clarity of this additional statement in the Virginia State Crash Report Manual we did not feel that we could assume these police officers intended for "Not Applicable" to mean "No Restraint Used" and therefore considered these data as incorrectly coded. However, some useful statistics can still be obtained from this variable; the overall helmet use rate can be calculated as $51.8 \%$. Cross tabulation of bicyclist drinking and helmet use yields interesting results. Using the modeling dataset with 2435 cases, among bicyclists that had been drinking, $8.2 \%$ wore helmets. This is in stark contrast to the $53.5 \%$ of sober bicyclists that wore helmets. Furthermore, across genders, males have a helmet use rate of $50.3 \%$, lower than the female helmet use rate of $58.2 \%$.

A final note about this dataset, there is no category in this table for automobile driver fatalities, because none occurred in the dataset.

TABLE 2 Vehicle, Roadway, Environment, and Location Descriptive Statistics

\begin{tabular}{|c|c|c|c|c|c|c|c|}
\hline \multicolumn{2}{|l|}{ Variables } & $\begin{array}{l}\text { Fatal } \\
\text { Injury }\end{array}$ & $\begin{array}{l}\text { Severe } \\
\text { Injury }\end{array}$ & $\begin{array}{l}\text { Minor/ } \\
\text { Possible } \\
\text { Injury }\end{array}$ & $\begin{array}{l}\text { No } \\
\text { Apparent } \\
\text { Injury }\end{array}$ & $\begin{array}{l}\text { No } \\
\text { Injury }\end{array}$ & Total $* *$ \\
\hline \multicolumn{8}{|c|}{ Vehicle Characteristics } \\
\hline $\begin{array}{l}\text { Continuous } \\
\text { Variable* }\end{array}$ & $\begin{array}{l}\text { Vehicle Speed } \\
\text { Before Crash in } \\
\mathrm{mph}(\mathrm{km} / \mathrm{h})\end{array}$ & $\begin{array}{l}34.1 \\
(54.9)\end{array}$ & $\begin{array}{l}19.8 \\
(31.9)\end{array}$ & $\begin{array}{l}13.5 \\
(21.7)\end{array}$ & $\begin{array}{l}11.3 \\
(18.2)\end{array}$ & $\begin{array}{l}15.4 \\
(24.8)\end{array}$ & $14.8(23.8)$ \\
\hline \multirow[t]{2}{*}{$\begin{array}{l}\text { Vehicle } \\
\text { Condition }\end{array}$} & Not Defective & $\begin{array}{l}19 \\
(1 \%)\end{array}$ & $\begin{array}{l}555 \\
(23 \%)\end{array}$ & $\begin{array}{l}1353 \\
(56 \%)\end{array}$ & $\begin{array}{l}434 \\
(18 \%)\end{array}$ & $\begin{array}{l}63 \\
(3 \%)\end{array}$ & $\begin{array}{l}2424 \\
(100 \%)\end{array}$ \\
\hline & Defective & $1(9 \%)$ & $2(18 \%)$ & $4(36 \%)$ & $3(27 \%)$ & $1(9 \%)$ & $11(0 \%)$ \\
\hline \multirow[t]{2}{*}{$\begin{array}{l}\text { Vehicle } \\
\text { Body Type }\end{array}$} & Small Vehicle & $0(0 \%)$ & $8(42 \%)$ & $8(42 \%)$ & $2(11 \%)$ & $1(5 \%)$ & $19(1 \%)$ \\
\hline & Passenger Car & $9(1 \%)$ & $\begin{array}{l}316 \\
(21 \%)\end{array}$ & $836(56 \%)$ & $\begin{array}{l}291 \\
(20 \%)\end{array}$ & $\begin{array}{l}40 \\
(3 \%)\end{array}$ & $1492(61 \%)$ \\
\hline
\end{tabular}




\begin{tabular}{|c|c|c|c|c|c|c|c|}
\hline & SUV/truck/van & $\begin{array}{l}10 \\
(1 \%)\end{array}$ & $\begin{array}{l}215 \\
(25 \%)\end{array}$ & $475(55 \%)$ & $\begin{array}{l}136 \\
(16 \%)\end{array}$ & $\begin{array}{l}20 \\
(2 \%)\end{array}$ & $856(35 \%)$ \\
\hline & Large Vehicle & $1(1 \%)$ & $18(26 \%)$ & $38(56 \%)$ & $8(12 \%)$ & $3(4 \%)$ & $68(3 \%)$ \\
\hline \multicolumn{8}{|c|}{ Roadway Characteristics } \\
\hline \multirow[t]{4}{*}{$\begin{array}{l}\text { Roadway } \\
\text { Description }\end{array}$} & $\begin{array}{l}\text { Two Way } \\
\text { Undivided }\end{array}$ & $\begin{array}{l}11 \\
(1 \%)\end{array}$ & $\begin{array}{l}330 \\
(26 \%)\end{array}$ & $701(55 \%)$ & $\begin{array}{l}201 \\
(16 \%)\end{array}$ & $\begin{array}{l}38 \\
(3 \%)\end{array}$ & $1281(53 \%)$ \\
\hline & $\begin{array}{l}\text { Two Way } \\
\text { Divided } \\
\text { Unprotected }\end{array}$ & $5(1 \%)$ & $\begin{array}{l}133 \\
(20 \%)\end{array}$ & $391(58 \%)$ & $\begin{array}{l}125 \\
(19 \%)\end{array}$ & $\begin{array}{l}17 \\
(3 \%)\end{array}$ & $671(28 \%)$ \\
\hline & $\begin{array}{l}\text { Two Way } \\
\text { Divided Median }\end{array}$ & $4(1 \%)$ & $79(20 \%)$ & $217(55 \%)$ & $88(22 \%)$ & $8(2 \%)$ & $396(16 \%)$ \\
\hline & One Way & $0(0 \%)$ & $15(17 \%)$ & $48(55 \%)$ & $23(26 \%)$ & $1(1 \%)$ & $87(4 \%)$ \\
\hline \multirow[t]{2}{*}{$\begin{array}{l}\text { Roadway } \\
\text { Surface } \\
\text { Type } \\
\end{array}$} & Concrete/Asphalt & $\begin{array}{l}20 \\
(1 \%)\end{array}$ & $\begin{array}{l}556 \\
(23 \%)\end{array}$ & $\begin{array}{l}1352 \\
(56 \%)\end{array}$ & $\begin{array}{l}433 \\
(18 \%)\end{array}$ & $\begin{array}{l}63 \\
(3 \%)\end{array}$ & $\begin{array}{l}2424 \\
(100 \%)\end{array}$ \\
\hline & $\begin{array}{l}\text { Brick/Block/ } \\
\text { Gravel/Stone }\end{array}$ & $0(0 \%)$ & $1(9 \%)$ & $5(45 \%)$ & $4(36 \%)$ & $1(9 \%)$ & $11(0 \%)$ \\
\hline \multirow[t]{2}{*}{$\begin{array}{l}\text { Roadway } \\
\text { Surface } \\
\text { Condition }\end{array}$} & Dry & $\begin{array}{l}20 \\
(1 \%)\end{array}$ & $\begin{array}{l}520 \\
(23 \%)\end{array}$ & $\begin{array}{l}1273 \\
(56 \%)\end{array}$ & $\begin{array}{l}390 \\
(17 \%)\end{array}$ & $\begin{array}{l}58 \\
(3 \%)\end{array}$ & $2261(93 \%)$ \\
\hline & Wet & $0(0 \%)$ & $37(23 \%)$ & $84(48 \%)$ & $47(27 \%)$ & $6(3 \%)$ & $174(7 \%)$ \\
\hline \multirow[t]{2}{*}{$\begin{array}{l}\text { Horizontal } \\
\text { Alignment } \\
\end{array}$} & Straight & $\begin{array}{l}17 \\
(1 \%) \\
\end{array}$ & $\begin{array}{l}507 \\
(22 \%) \\
\end{array}$ & $\begin{array}{l}1285 \\
(56 \%) \\
\end{array}$ & $\begin{array}{l}422 \\
(18 \%) \\
\end{array}$ & $\begin{array}{l}61 \\
(3 \%) \\
\end{array}$ & $2292(94 \%)$ \\
\hline & Curve & $3(2 \%)$ & $50(35 \%)$ & $72(50 \%)$ & $15(10 \%)$ & $3(2 \%)$ & $143(6 \%)$ \\
\hline \multirow[t]{3}{*}{$\begin{array}{l}\text { Vertical } \\
\text { Alignment }\end{array}$} & Level & $\begin{array}{l}15 \\
(1 \%) \\
\end{array}$ & $\begin{array}{l}416 \\
(21 \%) \\
\end{array}$ & $\begin{array}{l}1108 \\
(56 \%) \\
\end{array}$ & $\begin{array}{l}383 \\
(19 \%) \\
\end{array}$ & $\begin{array}{l}48 \\
(2 \%) \\
\end{array}$ & $1970(81 \%)$ \\
\hline & Grade & $3(1 \%)$ & $\begin{array}{l}122 \\
(31 \%)\end{array}$ & $210(54 \%)$ & $42(11 \%)$ & $\begin{array}{l}14 \\
(4 \%)\end{array}$ & $391(16 \%)$ \\
\hline & Hillcrest/Dip & $2(3 \%)$ & $19(26 \%)$ & $39(53 \%)$ & $12(16 \%)$ & $2(3 \%)$ & $74(3 \%)$ \\
\hline \multicolumn{8}{|c|}{ Environmental Characteristics } \\
\hline \multirow[t]{6}{*}{$\begin{array}{l}\text { Light } \\
\text { Condition } \\
\end{array}$} & Dawn & $1(3 \%)$ & $6(16 \%)$ & $21(57 \%)$ & $6(16 \%)$ & $3(8 \%)$ & $37(2 \%)$ \\
\hline & Daylight & $\begin{array}{l}13 \\
(1 \%)\end{array}$ & $\begin{array}{l}437 \\
(23 \%)\end{array}$ & $\begin{array}{l}1097 \\
(57 \%)\end{array}$ & $\begin{array}{l}324 \\
(17 \%)\end{array}$ & $\begin{array}{l}46 \\
(2 \%)\end{array}$ & $1917(79 \%)$ \\
\hline & Dusk & $2(2 \%)$ & $22(24 \%)$ & $42(47 \%)$ & $22(24 \%)$ & $2(2 \%)$ & $90(4 \%)$ \\
\hline & $\begin{array}{l}\text { Darkness-Road } \\
\text { Lighted }\end{array}$ & $1(0 \%)$ & $66(23 \%)$ & $146(50 \%)$ & $68(23 \%)$ & $9(3 \%)$ & $290(12 \%)$ \\
\hline & $\begin{array}{l}\text { Darkness-Road } \\
\text { Not Lighted }\end{array}$ & $3(3 \%)$ & $24(26 \%)$ & $49(52 \%)$ & $15(16 \%)$ & $3(3 \%)$ & $94(4 \%)$ \\
\hline & $\begin{array}{l}\text { Darkness- } \\
\text { Unknown } \\
\text { Lighting }\end{array}$ & $0(0 \%)$ & $2(33 \%)$ & $2(33 \%)$ & $2(33 \%)$ & $0(0 \%)$ & $6(0 \%)$ \\
\hline \multirow[t]{2}{*}{$\begin{array}{l}\text { Weather } \\
\text { Condition }\end{array}$} & No Precipitation & $\begin{array}{l}20 \\
(1 \%)\end{array}$ & $\begin{array}{l}530 \\
(23 \%) \\
\end{array}$ & $\begin{array}{l}1283 \\
(56 \%) \\
\end{array}$ & $\begin{array}{l}394 \\
(17 \%) \\
\end{array}$ & $\begin{array}{l}58 \\
(3 \%) \\
\end{array}$ & $2285(94 \%)$ \\
\hline & Precipitation & $0(0 \%)$ & $27(18 \%)$ & $74(49 \%)$ & $43(29 \%)$ & $6(4 \%)$ & $150(6 \%)$ \\
\hline \multicolumn{8}{|c|}{ Location Characteristics } \\
\hline $\begin{array}{l}\text { Intersection } \\
\text { Type }\end{array}$ & No Intersection & $\begin{array}{l}12 \\
(2 \%)\end{array}$ & $\begin{array}{l}217 \\
(28 \%) \\
\end{array}$ & $422(54 \%)$ & $\begin{array}{l}108 \\
(14 \%)\end{array}$ & $\begin{array}{l}19 \\
(2 \%) \\
\end{array}$ & $778(32 \%)$ \\
\hline
\end{tabular}




\begin{tabular}{|l|l|l|l|l|l|l|l|}
\hline & Two Approaches & $0(0 \%)$ & $42(24 \%)$ & $101(57 \%)$ & $33(19 \%)$ & $2(1 \%)$ & $178(7 \%)$ \\
\hline & $\begin{array}{l}\text { Three } \\
\text { Approaches }\end{array}$ & $3(1 \%)$ & $\begin{array}{l}111 \\
(19 \%)\end{array}$ & $340(57 \%)$ & $\begin{array}{l}123 \\
(21 \%)\end{array}$ & $\begin{array}{l}18 \\
(3 \%)\end{array}$ & $595(24 \%)$ \\
\hline & $\begin{array}{l}\text { Four Plus } \\
\text { Approaches }\end{array}$ & $5(1 \%)$ & $\begin{array}{l}187 \\
(21 \%)\end{array}$ & $491(56 \%)$ & $\begin{array}{l}173 \\
(20 \%)\end{array}$ & $\begin{array}{l}25 \\
(3 \%)\end{array}$ & $881(36 \%)$ \\
\hline & Roundabout & $0(0 \%)$ & $0(0 \%)$ & $3(100 \%)$ & $0(0 \%)$ & $0(0 \%)$ & $3(0 \%)$ \\
\hline School Zone & $\begin{array}{l}\text { Not in School } \\
\text { Zone }\end{array}$ & $\begin{array}{l}20 \\
(1 \%)\end{array}$ & $\begin{array}{l}545 \\
(23 \%)\end{array}$ & $\begin{array}{l}1317 \\
(56 \%)\end{array}$ & $\begin{array}{l}423 \\
(18 \%)\end{array}$ & $\begin{array}{l}63 \\
(3 \%)\end{array}$ & $2368(97 \%)$ \\
\hline & $\begin{array}{l}\text { In or Near } \\
\text { School Zone }\end{array}$ & $0(0 \%)$ & $12(18 \%)$ & $40(60 \%)$ & $14(21 \%)$ & $1(1 \%)$ & $67(3 \%)$ \\
\hline $\begin{array}{l}\text { Work Zone } \\
\text { Location }\end{array}$ & $\begin{array}{l}\text { Not in Work } \\
\text { Zone }\end{array}$ & $\begin{array}{l}20 \\
(1 \%)\end{array}$ & $\begin{array}{l}554 \\
(23 \%)\end{array}$ & $\begin{array}{l}1346 \\
(56 \%)\end{array}$ & $\begin{array}{l}437 \\
(18 \%)\end{array}$ & $\begin{array}{l}62 \\
(3 \%)\end{array}$ & $2419(99 \%)$ \\
\hline & $\begin{array}{l}\text { Zear or In Work } \\
\text { Zone }\end{array}$ & $0(0 \%)$ & $3(19 \%)$ & $11(69 \%)$ & $0(0 \%)$ & $\begin{array}{l}2 \\
(13 \%)\end{array}$ & $16(1 \%)$ \\
\hline $\begin{array}{l}\text { Traffic } \\
\text { Control }\end{array}$ & $\begin{array}{l}\text { Working } \\
\text { Wrablem with } \\
\text { traffic control }\end{array}$ & $\begin{array}{l}19 \\
(1 \%)\end{array}$ & $\begin{array}{l}406 \\
(22 \%)\end{array}$ & $\begin{array}{l}1039 \\
(56 \%)\end{array}$ & $\begin{array}{l}330 \\
(18 \%)\end{array}$ & $\begin{array}{l}54 \\
(3 \%)\end{array}$ & $1848(76 \%)$ \\
\hline & No traffic control & $1(0 \%)$ & $\begin{array}{l}143 \\
(25 \%)\end{array}$ & $312(55 \%)$ & $\begin{array}{l}104 \\
(18 \%)\end{array}$ & $9(2 \%)$ & $569(23 \%)$ \\
\hline
\end{tabular}

*Continuous variables are presented with means in $\mathrm{mph}$ and $\mathrm{km} / \mathrm{h}$ in place of frequencies and percentages **Percentages in totals column for variables not used in the model may not sum to $100 \%$ due to missing data

Other crash statistics involve vehicle, roadway, and environmental characteristics. Passenger cars are the most common type of vehicle in automobile-bicycle crashes (61\%), coming in second are SUVs, light duty trucks, and vans, which together account for 35\%. Vehicle speed before crash is a variable that is prone to estimation error as it is determined by the police officer after examining the physical evidence at the scene and interviewing the automobile driver. However, speed is an important factor in defining the dynamics of the crash. Roadway characteristics show that $32 \%$ of crashes occurred at non-intersection locations and $60 \%$ occurred at intersections with three or more approaches. Roadway characteristics also show that most crashes occur on concrete or asphalt roads in dry conditions, on straight and level roads. Environmental characteristics show that the majority of crashes (79\%) occurred during daylight hours and $6 \%$ of crashes occurred when the weather involved precipitation (fog, mist, rain, or snow).

\subsection{METHODOLOGY}

With an understanding of the nuances of this particular dataset and tendencies in bicycle crash data, the ordered probit (OP) model was chosen to analyze the data. As discussed by Ye and Lord (2014), the most common injury severity models (multinomial logit model [MNL], OP, and mixed logit) are limited by a minimum reasonable sample size. Ye and Lord (2014) used a Monte-Carle approach and determined that minimum sample sizes of 1000, 2000, and 5000 are suggested for the OP, MNL, and mixed logit models, respectively. By this logic, the sample size of the Virginia crash dataset for the time period currently available (2010-2014) does not afford itself to the use of a mixed logit model. Both MNL and OP models were considered here, with the OP specification yielding a better model fit, which reflects the ordered nature of injury severities.

In this study, the response variable is the injury severity of the bicyclist in the crash, represented by the following five categories: fatal (0), severe injury (1), minor/possible injury (2), no apparent injury (3), and no injury (4). The crash, roadway, environment, vehicles (bikes and automobiles), and drivers (cyclists and automobile drivers) characteristics are the independent variables in the model. Initially, $\mathrm{y}^{*}$ is 
calculated as a function of crash characteristics and calculated coefficients as in equation (1) (Greene, 2008).

$$
y^{*}=x^{\prime} \beta+\varepsilon
$$

Where $\mathrm{x}$ represents the crash characteristic variables (cyclists, drivers, vehicles, roadway, environment), $\beta$ represents the estimated coefficients, and $\mathrm{Y}$ is the response variable. The injury category a crash falls into is determined by the following equations (Greene, 2008):

$$
\begin{array}{clc}
Y=0 & \text { if } & y^{*} \leq 0 \\
Y=1 & \text { if } & 0 \leq y^{*} \leq u_{1} \\
Y=2 & \text { if } & u_{1} \leq y^{*} \leq u_{2} \\
Y=3 & \text { if } & u_{2} \leq y^{*} \leq u_{3} \\
Y=4 & \text { if } & y^{*} \geq u_{3}
\end{array}
$$

Where $\mathrm{u}_{\mathrm{i}}$ are bounds unique to each injury severity level. The probability of an observation falling into an injury category is determined using the following equations (Greene, 2008):

$$
\begin{gathered}
\operatorname{Prob}(y=0 \mid x)=\Phi\left(-x^{\prime} \beta\right) \\
\operatorname{Prob}(y=1 \mid x)=\Phi\left(u_{1}-x^{\prime} \beta\right)-\Phi\left(-x^{\prime} \beta\right) \\
\operatorname{Prob}(y=2 \mid x)=\Phi\left(u_{2}-x^{\prime} \beta\right)-\Phi\left(u_{1}-x^{\prime} \beta\right) \\
\operatorname{Prob}(y=3 \mid x)=\Phi\left(u_{3}-x^{\prime} \beta\right)-\Phi\left(u_{2}-x^{\prime} \beta\right) \\
\operatorname{Prob}(y=4 \mid x)=1-\Phi\left(u_{3}-x^{\prime} \beta\right)
\end{gathered}
$$

These analyses were performed using two statistical software products; IBM SPSS was used for data cleaning and descriptive statistics and STATA was utilized for ordered probit model analysis.

\subsection{RESULTS AND DISCUSSION}

The results from the OP bicyclist injury severity model are shown in Table 3. Coefficients, standard errors, and level of significance are presented for each variable included in the model.

\section{TABLE 3 Injury Severity Model Results}

\begin{tabular}{|l|l|l|l|l|}
\hline Variables & Coefficient & Std. Err. & $\mathrm{Z}$ & \\
\hline Bicycle Characteristics & & & & \\
\hline Bicycle Speed Before Crash & -.0061907 & .0035281 & -1.75 & $*$ \\
\hline Bicyclist Drinking & -.2346965 & .1008416 & -2.33 & $* *$ \\
\hline Automobile Driver Characteristics & & & & \\
\hline Vision Obscured & -.1652214 & .0598915 & -2.76 & $* * *$ \\
\hline Driver Drinking & -.6575973 & .1993321 & -3.30 & $* * *$ \\
\hline Vehicle Characteristics & & & & \\
\hline Vehicle Speed Before Crash & -.0096984 & .0013482 & -7.19 & $* * *$ \\
\hline Vehicle Body Type Small & -.2717863 & .2551485 & -1.07 & \\
\hline Vehicle Body Type SUV Truck Van & -.1363347 & .0473466 & -2.88 & $* * *$ \\
\hline Vehicle Body Type Large & -.1671854 & .1368371 & -1.22 & \\
\hline Environmental Characteristics & & & & \\
\hline Precipitation & .3278165 & .0927334 & 3.54 & $* * *$ \\
\hline Roadway Characteristics & & & & \\
\hline Two Way Divided Unprotected & .1136306 & .0529959 & 2.14 & $* *$ \\
\hline Two Way Divided Median & .1092572 & .0641529 & 1.70 & $*$ \\
\hline
\end{tabular}




\begin{tabular}{|l|l|l|l|l|}
\hline One Way & .2930788 & .1240449 & 2.36 & $* *$ \\
\hline Vertical Alignment Grade & -.1970375 & .0635584 & -3.10 & $* * *$ \\
\hline Vertical Alignment Hillcrest and Dip & -.0705976 & .1312457 & -0.54 & \\
\hline Horizontal Align Curve & -.2291624 & .0973484 & -2.35 & $* *$ \\
\hline Roadway Surface Untraditional & .6910561 & .3288138 & 2.10 & $* *$ \\
\hline Two Approaches & -.0002326 & .0935231 & -0.00 & \\
\hline Three Approaches & .2118217 & .0610402 & 3.47 & $* * *$ \\
\hline Four Plus Approaches & .1373155 & .0555327 & 2.47 & $* *$ \\
\hline Roundabout & .0307574 & .6477156 & 0.05 & \\
\hline & & & & \\
\hline $\mathrm{u}_{1}$ & -2.692099 & .1066522 & & \\
\hline $\mathrm{u}_{2}$ & -.9025529 & .066111 & & \\
\hline $\mathrm{u}_{3}$ & .7052992 & .0652531 & & \\
\hline $\mathrm{u}_{4}$ & 1.841915 & .0792975 & & \\
\hline
\end{tabular}

*statistically significant at $90 \%$ confidence interval

$* *$ statistically significant at $95 \%$ confidence interval

$* * *$ statistically significant at $99 \%$ confidence interval

To properly interpret the above variables and their practical significance on the probability of a case being in each of the five injury severity categories, marginal effects were calculated and are presented in Table 4. For binary variables, the table gives the difference in probability of an outcome as a variable is changed from zero (the base case) to one. For continuous variables, the table gives the difference in probability of an outcome as the variable changes from the mean to one standard deviation above the mean. All variables other than the one whose marginal effect is being calculated are held at standard means. For example, if a bicyclist is drinking, the probability of a fatal crash increases from $0.314 \%$ to $0.625 \%$ which is 0.31 percentage points greater than if they had not been drinking, or a $98.8 \%$ increase. Marginal effects are presented in Table 4 and percentage increases are referenced in the following discussion.

TABLE 4 Marginal Effects

\begin{tabular}{|c|c|c|c|c|c|}
\hline & \multicolumn{5}{|c|}{ Marginal Effect, Change of Probabilities Versus Base Case } \\
\hline Variables & Fatal (1) & $\begin{array}{l}\text { Severe } \\
(2)\end{array}$ & $\begin{array}{l}\text { Minor/ } \\
\text { Possible (3) }\end{array}$ & $\begin{array}{l}\text { No apparent } \\
\text { (4) }\end{array}$ & $\begin{array}{l}\text { No Injury } \\
(5)\end{array}$ \\
\hline \multicolumn{6}{|l|}{ Bicyclist Characteristics } \\
\hline \multicolumn{6}{|c|}{ Continuous Variables (increased by 1 standard deviation from mean) } \\
\hline Bicycle Speed Before Crash & 0.0004 & 0.0104 & 0.0014 & -0.0094 & -0.0029 \\
\hline \multicolumn{6}{|c|}{ Bicyclist Drinking (compared to Bicyclist not Drinking) } \\
\hline Bicyclist Drinking & 0.0031 & 0.0649 & -0.0008 & -0.0529 & -0.0143 \\
\hline \multicolumn{6}{|c|}{ Automobile Driver characteristics } \\
\hline \multicolumn{6}{|c|}{ Visibility (compared to Vision Not Obscured) } \\
\hline Vision Obscured & 0.0019 & 0.0441 & 0.0032 & -0.0381 & -0.0110 \\
\hline \multicolumn{6}{|c|}{ Drinking (compared to Driver not Drinking) } \\
\hline Driver Drinking & 0.0161 & 0.2028 & -0.0645 & -0.1271 & -0.0272 \\
\hline \multicolumn{6}{|l|}{ Automobile characteristics } \\
\hline \multicolumn{6}{|c|}{ Continuous Variables (increased by 1 standard deviation from mean) } \\
\hline Vehicle Speed Before Crash & 0.0020 & 0.0442 & 0.0011 & -0.0370 & -0.0103 \\
\hline Vehicle Body Type (compar & senger & icle) & & & \\
\hline
\end{tabular}




\begin{tabular}{|l|l|l|l|l|l|}
\hline Vehicle Body Type Small Body Type & 0.0039 & 0.0767 & -0.0048 & -0.0602 & -0.0157 \\
\hline $\begin{array}{l}\text { Vehicle } \\
\text { SUV/Truck/Van }\end{array}$ & 0.0354 & 0.0048 & -0.0319 & -0.0097 \\
\hline Vehicle Body Type Large & 0.0021 & 0.0455 & 0.0013 & -0.0382 & -0.0107 \\
\hline Environmental Characteristics & & & & \\
\hline Precipitation (compared to No Precipitation) & & & \\
\hline Precipitation & -0.0022 & -0.0735 & -0.0353 & 0.0797 & 0.0314 \\
\hline Roadway Characteristics & & & \\
\hline Roadway Type (compared to Two Way Undivided) & & & \\
\hline Two Way Divided Unprotected & -0.0011 & -0.0284 & -0.0063 & 0.0271 & 0.0088 \\
\hline Divided Median & -0.0010 & -0.0271 & -0.0067 & 0.0261 & 0.0086 \\
\hline One Way & -0.0020 & -0.0662 & -0.0307 & 0.0713 & 0.0277 \\
\hline Vertical Alignment (compared to Level Roads) & & & \\
\hline Vertical Alignment Grade & 0.0024 & 0.0531 & 0.0026 & -0.0452 & -0.0129 \\
\hline Vertical Alignment Hillcst/Dip & 0.0008 & 0.0185 & 0.0020 & -0.0165 & -0.0049 \\
\hline Horizontal Alignment (compared to Straight Roads) & & & \\
\hline Horizontal Alignment Curve & 0.0030 & 0.0633 & -0.0005 & -0.0517 & -0.0140 \\
\hline Roadway Surface (compared to Asphalt/Concrete) & & & \\
\hline Roadway Surface Untraditional & -0.0030 & -0.1255 & -0.1247 & 0.1611 & 0.0922 \\
\hline Intersection (compared to No Intersection) & & & & \\
\hline Two Approaches & 0.0000 & 0.0001 & 0.0000 & -0.0001 & 0.0000 \\
\hline Three Approaches & -0.0018 & -0.0516 & -0.0147 & 0.0508 & 0.0173 \\
\hline Four Plus Approaches & -0.0013 & -0.0345 & -0.0073 & 0.0326 & 0.0105 \\
\hline Roundabout & -0.0003 & -0.0078 & -0.0016 & 0.0073 & 0.0023 \\
\hline
\end{tabular}

\subsubsection{Bicyclist Characteristics}

\subsubsection{Bicycle Speed}

The speed at which the bicycle was traveling at the time of the crash affects the injury severity levels. As shown in table 4, a one standard deviation increase in bicyclist travel speed $(6.49 \mathrm{mph})$ increases the probability of both a fatality and severe injury, by 0.0004 (12.8\%) and $0.0104(5.8 \%)$, respectively. This is an intuitive finding considering the physics of momentum, and the capability of the bicyclist to stop or swerve to avoid a collision is more difficult at higher travel speeds. According to the Virginia State Crash Report Manual, the bicycle speed variable is collected "by examining physical evidence and interviewing witnesses" (Virginia DMV, 2015). Therefore, participants or witnesses to the crash may give input on how this variable is recorded. This method introduces some subjectivity into the bicycle speed data, but nonetheless provides estimated information on a significant variable in injury outcomes.

\subsubsection{Bicyclist Drinking}

In crashes where the bicyclist is under the influence of alcohol, the likelihood of a fatality increases by $0.0031(98.8 \%)$ and a severe injury increases by $0.0649(36.7 \%)$. This finding is consistent with those of Kim et al. (2007) where the probability of a fatal injury was found to double if the bicyclist was intoxicated. Additionally, among fatally injured bicyclists in this dataset, $21.4 \%$ were found to have been drinking. This is consistent with findings from the National Center for Statistics and Analysis (NCSA) report (2016) that found $24 \%$ of bicyclists killed in 2014 had a BAC of $0.01 \mathrm{~g} / \mathrm{dL}$ or higher, with $21 \%$ of those being $0.08 \mathrm{~g} / \mathrm{dL}$ or higher (the legal limit for driving under the influence in Virginia). Furthermore, 
as previously discussed, fatal crashes in this dataset have a missing data rate for bicyclist drinking of 37.8\% compared to $10.1 \%$ for all other injury severity levels. Therefore, this finding may still be underestimating the impact of bicyclist drinking on the likelihood of a fatal crash. The state of Virginia does not currently have laws specifically prohibiting bicycling under the influence (BUI). Virginia driving under the influence (DUI) laws are written to apply to motor vehicles, and would appear to exempt bicyclists from DUI's by defining bicycles as vehicles and not as motor vehicles (McLeod, 2013). As bicyclist intoxication is found in this study to double the probability of severe injuries and increase probability of bicyclist death, an examination of whether these laws are effective may be warranted.

Another facet of this variable is that among the bicyclists who had been drinking, helmet use rates were considerably lower than sober cyclists. Only $8.2 \%$ of intoxicated bicyclists wore helmets, whereas the helmet use rate among sober bicyclists was $53.5 \%$. This is a finding that has previously been uncovered using data from medical records in studies by Sethi et al. (2016) and Andersson and Bunketorp (2002) who found intoxicated cyclists less likely to wear helmets and more likely to be severely injured (Sethi et al., 2016) or obtain head and face injuries (Andersson and Bunketorp, 2002). Although this model did not find helmet use to be a factor in injury severity, possibly due to the high percentage of missing data, the low helmet use among intoxicated bicyclists may be in part attributing to the increased probability of severe injuries predicted by this variable.

\subsubsection{Automobile Driver Characteristics}

\subsubsection{Vision Obscured}

When the automobile driver has his/her vision obscured (by rain, snow, trees, buildings, other vehicles, glare, blind spots, hillcrests, signs, etc.) and are in a crash with a bicyclist, the bicyclist's fatality and severe injury risks increase by $0.0441(25.5 \%)$ and $0.0019(63.4 \%)$ respectively. When a driver's ability to see a bicyclist is compromised, he or she may have less time to react before the crash, resulting in greater speeds upon collision. This finding supports the importance of visibility of bicyclists. Virginia laws require bike lights on the front of the vehicle and reflectors on the back, but only at night (VDOT, 2016). It could be beneficial to investigate the effectiveness of these laws to determine if they improve bicyclist safety by increasing the visibility of those who adhere to them.

\subsubsection{Driver Drinking}

An intoxicated automobile driver increases the likelihood of both fatal and severe injuries for cyclists by 0.0161 (502.4\%) and 0.2028 (113.9\%) respectively. Moore et al. (2011) and Kim et al. (2007) also found an automobile driver under the influence of alcohol to increase the probabilities of severe and fatal injuries to the cyclist. Moore et al. (2011) found the probability of a severe injury to increase by $82.2 \%$ or $150.1 \%$ depending on if the crash occurred in an intersection or not. Kim et al. (2007) found the probability of death to more than double if either cyclist or driver were intoxicated. While intoxication from either the bicyclist or the automobile driver is shown here to increase severe and fatal injuries, the driver's alcohol use has greater impact on cyclist injuries. A crash involving a drunk driver increases the probability of cyclist fatalities by 0.0161 (502.4\%) compared to $0.0031(36.7 \%)$ when the bicyclist is intoxicated. The probability of a severe injury increases by $0.2028(113.9 \%)$ and $0.0649(98.8 \%)$ when the automobile driver or bicyclist are intoxicated respectively. This result is intuitive considering the significant mass advantage of the automobile compared to the bike in a crash.

\subsubsection{Vehicle Characteristics}

\subsubsection{Vehicle Speed}

Similar to the speed of the bicycle, higher automobile speeds at the time of the crash increases the probability of a cyclist fatality or severe injury. A one standard deviation increase $(16.7 \mathrm{mph})$ in automobile speed from the average $(14.7 \mathrm{mph})$ increases bicyclist fatality risk by $0.0020(61.4 \%)$ and severe injury risk by $0.0442(24.5 \%)$. This is consistent with the findings of many previous studies (see, for example, 5, 7, 8 
and Moore et al., 2011). With automobile speeds above $30 \mathrm{mph}$, Kim et al. (2007) found that the fatality risk of a bicyclist doubled. When automobile speeds were estimated above $50 \mathrm{mph}$, the fatality risk increased by a factor of 16 (2007).

\subsubsection{Vehicle Body Type}

Vans, SUVs, and light duty trucks are more likely to be involved in crashes where bicyclists experience fatal and severe injuries compared to passenger cars (sedans), with risks increasing by 0.0014 $(50.6 \%)$ and $0.0354(21.1 \%)$ for severe and fatal injuries respectively. This is logical because vans, SUVs, and light duty trucks are typically heavier than passenger cars and would exert more force on an unprotected bicyclist. However, compared to bicycles, passenger cars still have significant mass advantages. Longhitano et al. (2005) found that in crashes with pedestrians, vans, SUVs, and light trucks most commonly result in a head injury, followed by torso injuries. Longhitano et al. also found that for passenger vehicles, the most common result is also a head injury, followed by lower extremity injuries. Cyclists colliding with vehicles may also experience distinct injury patterns with different types of vehicles, as a result of the physical structure of the vehicle. Sedans tend to have a lower front, whereas SUVs, trucks, and vans are higher, resulting in a different impact point on the bicyclist or pedestrian.

\subsubsection{Environmental Characteristics}

\subsubsection{Weather}

This model shows that when precipitation (fog, mist, rain, or snow) is present in a crash between an automobile and a bicycle, the probability of no apparent injury increases by 0.0797 (39.7\%), no injury increases by $0.0314(99.5 \%)$, and probability of death decreases by $0.0022(-64.5 \%)$. This is not intuitive, as one might expect inclement weather to foster more dangerous riding conditions (as previously found by Kim et al. [2007]).

However, a possible explanation is that in these types of weather conditions, automobiles and bicyclists are traveling with extra caution, resulting in lower injury severity levels. This result is commonly found in analysis for automobile only crashes (Wang and Kockelman, 2005; Chen and Kockelman, 2012). Wang and Kockelman (2005) found bad weather to reduce the probability of injury and death in one and two car crashes. Chen and Kockelman (2012) also found single automobile crashes to be safer in adverse weather, decreasing the probability of a fatality by 29 percent. Furthermore, Khattak, Kantor, and Council (1998) determined that drivers likely compensate for adverse weather conditions, as their study showed that in adverse weather crashes tended to be more frequent but less severe in terms of injuries.

\subsubsection{Roadway Characteristics}

\subsubsection{Roadway Description}

The results of this model suggest that compared to a two-way undivided road, all other types of roads are less dangerous for bicyclists (two-way divided with no median, two-way divided with median, and one-way). Crashes occurring on two-way divided roads with or without a median and one-way roads are less likely to result in fatalities, severe injuries, or minor injuries. The probability of a fatality is reduced by $0.0011(-29.3 \%), 0.0010(-28.4 \%)$, and 0.0020 (-60.3\%) for divided roads with no median, divided roads with a median, and one-way roads, respectively. Additionally, the risk of a severe injury for divided roads with no median, divided roads with a median, and one-way roads decreases by $0.0284(-15.1 \%), 0.0271$ ($14.6 \%)$, and $0.0662(-36.2 \%)$, respectively. There may be several explanations for this occurrence. Kim et al. (2007) provide the explanation that on divided roads, bicyclists are less likely to ride against traffic, resulting in fewer head on crashes. On a two-way divided road with a median, the bicyclist cannot interact with the opposing flow of traffic unless the automobile crosses the median or the bicyclist is riding on the wrong side of the road against traffic. On a two-way divided road with no median, there is still some amount of division through a buffer, like a left turn lane. This separation may reduce conflict between the bicyclist and automobile traffic. These findings are supported by Kim et al. (2007), where two-way divided roads 
were found to reduce injury severity. It is important to recall that due to lack of exposure data, the analysis does not account for the differences in vehicle miles traveled on different types of roadways (with distinct features).

\subsubsection{Vertical Alignment}

Crashes that occur on roads with a grade are more likely to result in fatal and severe injuries than those on level roads. The probability of bicyclist death increases by $0.0024(79.2 \%)$ and severe injury increases by 0.0531 (30.8\%). This may be a result of reduced sight distance of the automobile. Additionally, bicyclists experience decreased ability to slow down or stop on downhill grades without destabilizing the bike. As discussed previously, obscured vision and increased speeds from both the automobile and the bicyclist increase the probability of a more severe injury. This finding corroborates those of Klop and Khattak's (1999) study that grades on straight and curved roads are detrimental to bike safety.

\subsubsection{Horizontal Alignment}

Compared to straight sections of road, crashes that occur on roads with a curve are $0.0030(95.7 \%)$ more likely to be fatal crashes and $0.0633(35.8 \%)$ more likely to be crashes with a severe injury. This can be explained by the automobile driver and the bicyclist's reduced sight distance as they travel around the curve. Minimized sight distance reduces the amount of time the automobile has to react if a bicyclist is in their path. Kim et al. (2007) also found that curved roadway geometry significantly increases the likelihood of a fatal or incapacitating injury. Kim et al. (2007) reasoned that curves reduce visibility and maneuverability of both the automobile and the bicyclist, resulting in a greater difficulty avoiding a dangerous crash.

\subsubsection{Roadway Surface}

Roads that are unpaved are less likely to be involved in fatal, severe, and minor injury crashes, with probabilities decreasing by $0.0030(-90.1 \%), 0.1255(-69.3 \%)$, and $0.1247(-21.6 \%)$ respectively. This specifically refers to brick, block, slag, gravel, stone, or dirt roads as compared to the smoother surfaces of concrete, asphalt, or blacktop roads. This finding could be explained by automobiles and bicycles likely traveling with more care on roads that are not smooth. Furthermore, bicyclists may be less likely to choose these routes due to riding discomfort.

\subsubsection{Intersections}

Model results suggest that at intersections with three or more approaches, crashes are less likely to result in fatalities and injuries as compared to non-intersection locations. At intersections with three approaches, the probability of death or severe injury decrease by $0.0018(-47.9 \%)$ and $0.0516(-26.7 \%)$, respectively. Similar results are observed at intersections with four or more approaches, where the probability of death or severe injury decreases by $0.0013(-34.1 \%)$ and $0.0345(-17.9 \%)$, respectively. These results support previous findings by Eluru et al. (2008), which determined that signalized intersections reduce the probability of a fatal bicyclist crash by almost $90 \%$. This may be attributed to increased alertness to conflict points among drivers and cyclists as they move through the intersection. Eluru et al. (2008) noted that it may be beneficial for common bike routes to be routed through intersections (for safety purposes) despite the inconvenience this would pose for bicyclists in terms of travel time. It is important to recall, however, that two-thirds of crashes in this dataset occurred at intersections compared to one-third on straight segments. Intersections may decrease likelihood of serious and fatal bicyclist injuries, but they still represent a major conflict point for bicyclists.

\subsection{CONCLUSIONS AND LIMITATIONS}

\subsubsection{Study Conclusions}


This study set out to identify risk factors for bicyclist injuries in bike-automobile crashes using a five-year statewide dataset from Virginia. Two of the most impactful results determined in this study are the influence of intoxicated bicyclists and drivers on injury severity outcomes. The results show that biking while inebriated doubles the probability of severe injury for the cyclist. Some states nationwide have adopted BUI laws in an attempt to quell occurrences of biking while intoxicated. If effective, BUI laws could impact the one quarter of bicyclist fatalities where alcohol is a factor. Some states would argue that BUI laws should not exist because an intoxicated automobile driver poses a greater risk to others than does a drunk bicyclist who is more likely to only injure themselves. Based on the lack of existing BUI analysis literature, this research indicates that further examination of BUI laws and their effectiveness may be warranted to determine their safety impact.

This study found that drunk drivers increase the fatality risk for cyclists more than any other factor studied. Laws designed to prevent DUIs already exist, and their effectiveness has been well documented. For example, Hingson, Heeren, and Winter (1996) verify the safety benefit of reducing the legal operating limit from a BAC of 0.10 to 0.08. In the same vain, Voas, Tippetts, and Fell (2003) determined the safety benefit from raising the minimum legal drinking age. However, it may be beneficial to improve education about the impacts drunk drivers pose not just to themselves and other automobiles, but to particularly vulnerable road users like bicyclists.

Designing roads to be forgiving to human error and are easy to safely navigate are primary goals of transportation engineers. Managing the dynamic between automobiles and bicyclists, vehicles with vastly different physical structures that require different roadway features to travel safely, is a challenge. This study found divided and one-way roads to be safer for bicyclists, possibly due to separation of traffic, reducing collisions with oncoming traffic, or to the increased width of divided roads and therefore improved maneuverability of cars and bikes to avoid conflicts as suggested by Kim et al. (2007). This highlights the incomplete understanding of how automobiles and bicyclists interact on the roadway, but also that dedicated bike lanes can reduce conflict between automobiles and bicyclists.

Additionally, study results suggest that when driver visibility was compromised, the probability of severe bicyclist injuries increased. The study also found roadway characteristics such as vertical grades and horizontal curves to be detrimental to the likelihood of severe injuries, possibly due to decreased sight distance before crashes, another component of visibility. Virginia has some laws facilitating bicyclist visibility; a headlight and rear reflectors are required when biking at night (VDOT, 2016). Rear lights could be added, or reflectors and lights could be required during daytime hours as well. A study by Madsen, Andersen, and Lahrmann (2013) determined that permanent running lights on bicycles can reduce the likelihood of a crash involving injury to the bicyclist. Another tactic to improve cyclist visibility is increased awareness about the presence of cyclists on roads. Signs and road markings indicating common bike paths may improve driver expectation of bicyclists on the road. Additionally, measures could be taken to avoid the conflict zone discussed by Rasanen and Summala (1997), where the most common bicycle automobile crash occurs when the driver looks left for oncoming cars but fails to look right for bicyclists waiting, also turning, or going straight. Signs alerting drivers to potential bicyclists in this zone in an intersection could be beneficial.

\subsubsection{Study Limitations}

Although the data yielded sensible results supported by past literature, the data are not without bias. The nature of the police-reporting process makes it likely that many minor or non-injury bike crashes are unreported in the dataset. Stutts and Hunter (1998) found a positive correlation between severity of bicyclist injury and likelihood of the crash being recorded by the police. It is therefore likely that in our dataset, no injury, no apparent injury and minor/possible injury crashes are underrepresented in the distribution of crashes. Additionally, it cannot be ignored that this analysis has been completed without access to any exposure data. As a result, it must be understood that this study presents an incomplete picture of bicyclist safety in Virginia, a challenge that currently cannot be overcome without a standardized statewide system for measuring intensity of bicycle travel. 
Furthermore, there are some specific variables that allow for bias and subjectivity. For example, the injury severity of the bicyclist (fatal, severe, minor etc.) is determined by the police officer at the scene of the crash. Mistakes certainly could have occurred in this process; an officer could classify an injury as "no apparent" if there was no visible wound but the bicyclist claimed of some pain. If the bicyclist later on found out there were broken bones, that injury should have been "severe". These types of subjective mistakes are impossible to eliminate from this dataset. Additionally, through the data cleaning process, it was determined that within the safety equipment variable (designed to collect data on bicyclist's helmet use), approximately one-third of the cases were incorrectly coded. Within this dataset, no other variable was so apparently miscoded. This highlights a widespread misunderstanding of how to report safety equipment used by the bicyclist. This component of the police crash reporting form should be re-evaluated.

\subsection{FURTHER RESEARCH}

The analysis of the Virginia police crash report data encouraged us to delve into the available information on bicycling under the influence laws and their impact. The first step we took into this process was to determine the current bicycling under the influence laws in the United States. It became apparent that BUI laws vary from state to state and that there is not any overarching federal legislation on BUI laws. There are 22 states plus the District of Columbia where the driving under the influence law is applicable to bicyclists. They are listed below:

- Alabama

- Colorado

- Connecticut

- Florida

- Georgia

- Hawaii

- Idaho

- Indiana

- Iowa

- Maryland

- Mississippi

- New Hampshire

- North Carolina

- North Dakota

- Ohio

- Oregon

- Pennsylvania

- Rhode Island

- Wyoming

- Utah

- Vermont

- Virginia

- District of Columbia

Additionally, there are 29 states where the driving under the influence law does not apply to bicyclists. The DUI law generally does not apply to bicyclists because the legislature is written so that it only applies to motorized vehicles and bicycle will be explicitly defined so that it does not fall in the category of motorized vehicles. Or the DUI law does not apply because bicyclists are specifically excluded from the application. The 24 states where the DUI law does not apply to bicyclists are as follows:

- Alaska

- Arizona

- Arkansas 
- Illinois

- Kansas

- Louisiana

- Maine

- Massachusetts

- Michigan

- Minnesota

- Missouri

- Montana

- Nebraska

- Nevada

- New Jersey

- New Mexico

- New York

- Oklahoma

- South Carolina

- South Dakota

- Tennessee

- Texas

- West Virginia

- Wisconsin

And finally, there are four states which have written their own laws specifically addressing the relationship between bicyclists and alcohol use. Those states are:

- California

- Delaware

- Kentucky

- Washington

The four states with BUI specific laws vary between states. In California, it is still illegal to bike under the influence but the punishment is not equivalent to a DUI charge. Biking under the influence in California can result in a misdemeanor and a fine but no jail time (Shouse, 2017). Similarly, in Delaware, bicycling under the influence is not legal but results in a lesser punishment than a DUI (Title 221, 1995). In Kentucky, the DUI law does not apply to bicyclists, but the same result is achieved because a separate law is written to explicitly state without ambiguity that bicycling under the influence is illegal (Galbraith). Finally, in the state of Washington, legislature was passed that makes bicycling under the influence legal, resulting in a similar outcome to that of states where the BUI does not apply to bicyclists (Act, 2000). After determining which types of laws apply to each state, the goal was to determine whether these laws or lack thereof have any safety benefit. To determine this, the most comprehensive nationwide crash database was consulted, the Fatality Analysis Reporting System (2015). This dataset is limited in that it only records fatal crashes, but it is comprehensive in that there is a very high recording rate and it is consistent across all fifty states. All available bicycle crash data for each state was downloaded along with information about levels of intoxication for the bicyclist. This dataset was limited in its size, as bicycle crashes are not as common as automobile crashes. Additionally, it was limited because blood alcohol content of the bicyclist was not tested in all cases, further limiting the dataset. This is not unexpected, as in fatal crashes the blood alcohol test would likely not be done through a simple breathalyzer test but rather at a hospital or during an autopsy. It could not be determined if there were statewide laws requiring blood alcohol content tests, and therefore there existed uncertainty in the data, where a person may have been labeled as having no BAC level, but actually they had not been tested and we could not know if that was true. Furthermore, over time BAC testing rates may have changed, becoming more common or less, information that would be difficult to track down. Additionally, we may have encountered an effect where BUI laws were implemented because 
of perceived problems with intoxicated bicyclists. In the end, these limitations proved to be an insurmountable problem and we could not achieve conclusive results because of the data quality. This is still an interesting question, and hopefully in the future more comprehensive crash data will enable further analysis of bicycling under the influence law effectiveness. 


\section{PART TWO - STATEWIDE SURVEY}

\subsection{INTRODUCTION}

After the completion of part one, the Virginia police crash report dataset analysis, we were encouraged to explore several avenues because of the results. As mentioned above, we tried to explore the impact of bicycling under the influence laws in the United States. In the past driving under the influence laws and their effectiveness have been thoroughly researched and a significant safety benefit of the laws was revealed (Hingson et al., 1996, Voas et al., 2003). Attempts to complete the same type of analysis for bicycle drinking laws were thwarted by the lack of data as bicycle crashes are less common than motor vehicle crashes. The next avenue explored after the results of Part One was to use surveys to construct our own bicycle dataset with the information we found lacking in police crash reports. As discussed in Part One, police crash reports are the most robust dataset available for examining bicycle crashes. This type of dataset presents some difficulties when being used to examine bicycle crashes. Inherently a database designed and most often used for cars, questions capture many important characteristics of bicycle crashes, with some exceptions. Bicycling safety information in the Virginia police databases are not well captured. Helmet information is highly flawed, and information about reflectors and lights are not captured. The greatest flaw in this dataset however may lie in the fact that many bicycle crashes just aren't in it. Underreporting of bicycle crashes to police is a widespread phenomenon worldwide (Shinar, 2016). Therefore, one goal of our survey is to capture more data on bicycle crashes, particularly those not in the police report database.

Additionally, police reported crash databases do not capture bicyclist and automobile driver attitudes about each other on the road, and bicyclist attitudes about their own safety. How safe people feel while biking is an important measure of safety, as it may influence people's willingness to ride and in turn the road safety and their motivation to advocate for infrastructure. Numerous studies have shown that the "safety in numbers" effect persists for bicyclists (Yao and Loo, 2016; Elvik and Bjornskau, 2017; Jacobsen, 2003). When more people are biking, the mode becomes safer. It may be reasoned that with more bikers, drivers become more accustomed to dealing with bikers on the road and learn to expect their presence and how they interact with cars. Affecting driver expectation may be what improves safety and therefore it is beneficial to understand what makes people feel safer and actually be safer on the roadway.

We chose to pursue a survey as a method for collecting information from bicyclists because we felt that it would be an efficient and effective way to gather crash, perception, and safety information from a large number of sources. Bicycling surveys have been distributed before, each with their own motives and goals for the design and results. We chose to design a survey that specifically captures the type of data that we found lacking in traditional bicycle data sources. This survey aimed to answer some of the limitations from the previous work on police reported crash data. We were able to review existing surveys and learn from their designs to build ours. The presentation and arrangement of a survey is very important, particularly for the type of survey where there is no interviewing phase, these surveys were all taken without assistance from the writers. Because of this the survey should be written very transparently so that respondents all interpret questions in the same way. Language must be extremely clear, the available responses must capture any way in which the respondent would like to answer, and the layout should not be too overwhelming so as to cause survey fatigue.

\subsection{SURVEY DEVELOPMENT}

\subsubsection{Survey Review}

A draft of the survey was sent to bicycle focused practitioners in Virginia to vet the questions, including members of the Virginia Transportation Research Council and Virginia bicycle and pedestrian planners. Their expertise from the bicycle community helped to ensure that the survey included meaningful 
questions and logical response choices. Additionally, a professional with survey expertise was consulted to help with clarity of questions and overall survey design.

\subsubsection{Survey Piloting}

The survey was piloted among biking and non-biking graduate students at the University of Virginia on several occasions to test coherence of questions, speed, and understanding. Additionally, as we are based in Charlottesville, Virginia, the Charlottesville Pedestrian and Bicycle Advisory Committee, a volunteer group in the city focusing on improving bicycle infrastructure design and safety. As stakeholders in the improvement of bike safety, the group vetted the survey and gave opinions on issues that from their perspective would be useful to have information about.

\subsubsection{Survey Distribution}

The survey was designed initially as a paper survey and then this design was converted to an online survey using Qualtrics Survey Software. The majority of the distribution relied on emails to numerous Virginia based bicycle organizations, clubs, and advocacy groups, and their completion of the online version of the survey. Additionally, with the goal of capturing responses from casual or non-bike riders, the survey was distributed locally at an event hosted during Bike Month in Charlottesville, Virginia. We expected that all types of bicyclists would be drawn to this type of public event. Additionally as the survey was occurring in a public area in Charlottesville we expected people to be present who were unaffiliated with the event and therefore possibly non-bikers. This distribution of the survey does not reflect a random sampling of the population, however we felt that in order to gain information from people in Virginia who bike we would need to target people using methods that would ensure the survey reached the bicycling community in Virginia. Research undertaken by Dill, McNeil, and Monsere (2016) at Portland State University analyzed this tendency of bicycle surveys to solicit responses specifically from groups known to bike to determine the effect on the results. Dill et al. (2016) found that this sampling method does yield statistically different responses to identical questions posed to a general random population. However, they found that in many cases the differences were small and may not have led to different conclusions. Therefore, our sampling method is one limitation of the overall research but we believe the results are valid nevertheless.

\subsubsection{Survey Weighting}

In order to improve how well the survey results represent the bicycling population in Virginia, we chose to weight our population to better reflect Virginia-wide demographics. In order to complete this step, 2008-2012 summary data on Travel Mode by Selected Social and Economic Characteristic was used from the American Community Survey (McKenzie, 2014). Because the information in this dataset refers to bicyclist commuters, it is an imperfect comparison to all Virginia bicyclists because it does not include the demographics of all other types of bicyclists who do not ride to work. However, we feel that the weighting step is important for our survey and that this data is the most comprehensive available and will reflect similar trends to the bicycling population overall. We chose to use information about age, sex, and education as weights for our sample. Age is an important weight because age affects the propensity for more severe injuries during a crash and therefore may affect the respondents' thoughts on various safety questions (2007). Because we know that in the United States the rate of female bicyclists is lower than that of male bicyclists, there must be inherent differences in perspective on the use of a bicycle that lead to this difference in number of bicyclists between the sexes. To capture these differences, we weighted our dataset based on sex. Additionally, we chose to use an education as a weight to capture different life perspectives, and perhaps how likely respondents are to know bicycle laws. The use of income as a weighting factor was also considered but ultimately discarded because of its correlation with education, because income is more prone to fluctuation than education, because the census income boundaries are more arbitrary than the clear-cut degree boundaries of education, and because many people chose not to provide income information in our survey. 


\subsubsection{Income Imputation}

In the demographics portion of the survey income was commonly ( $15 \%$ of the dataset) reported as "Prefer not to answer". To attempt to bolster the number of responses in this category for analysis, an imputation exercise was employed. We had also asked respondents for information about their location including zip code and two streets that form an intersection near their home. For respondents who gave zip code and intersection information but did not answer the question on income, we were able to geocode an address. The intersection and zip code were mapped, and an address very near the intersection was chosen to represent the respondents home address. Then the online census geocoder tool (Census Geocoder, 2017) was used, which accepts an address as an input, and gives information about the census tract as an output. Data from the American Community Survey consisting of 2015 5-year estimates of median income by census tract in Virginia was downloaded. The census tracts found using the geocoder, along with the initial zip code recorded by the survey respondent were matched to the ACS median income by census tract. In this way, we were able to approximate income levels for respondents who gave address but not income information.

\subsection{DATA}

The data used in this study was collected through the design and distribution of a bicycle safety and attitude survey throughout Virginia. The data was collected in the spring of 2017 mainly through online survey responses with some paper survey responses. A total of 686 survey responses were recorded, including people who began the survey but did not complete it. A total of 443 people completed the entire survey, including providing information for demographic questions. A true response rate cannot be estimated because the survey was posted numerous times on various social media outlets and therefore we cannot determine the number of people who were presented with the opportunity to take the survey. However, as the total of 686 survey responses includes people who clicked on the survey link but did not answer any questions we can estimate that approximately $65 \%$ of people who saw the survey completed it.

The survey captures a variety of data through questions on travel history, safety, past bicycle crashes, and demographics. The complete set of survey questions can be found in the appendix. The first section of the survey asks respondents to give information about their travel in the past week, including the transportation modes they have used and how often. The survey then segues into more bicycle focused questions, asking about the respondents recent biking history, and if there is none, why do the respondents choose not to bike. Then the survey moves into safety related questions. These consist of questions about the use of bicycle safety equipment (helmets, reflective clothing, lights), bicyclists experience with other drivers on the road, bicyclists comfort on bike infrastructure and roadways, and the crash history of the bicyclist. Finally, the survey concludes with standard survey demographic questions.

\subsubsection{Descriptive Statistics}

The questions on the bicycle safety survey are in several different forms allowing us to capture the appropriate type of data for the question. There are a series of questions that follow Likert scale responses (strongly agree, agree, neither agree or disagree, disagree, strongly disagree) and some that follow a similar five point response but capturing frequency rather than a level of feeling (always, usually, sometimes, rarely or never). The descriptive statistics for both of these types of questions can be seen in table 5. Furthermore, data with binary (yes, no) responses are shown in table 6. In all descriptive statistics tables, the dataset seen represents all responses in the dataset where the respondent completed at least half of the survey. This is to avoid giving information about respondents who were not included in any of the analysis and to avoid missing data from skewing percentages of responses. Although in the analyses different subsets were used depending on the level of missing data for each question, we have included all mostly complete responses here because each analysis technique may use a slightly different subset. As previously stated above 686 people began the survey, the descriptive statistics below give information for the 459 people who completed at least half of the survey.

TABLE 5 Descriptive characteristics of survey questions with multiple responses. 


\begin{tabular}{|c|c|c|c|c|c|c|c|c|c|}
\hline Question & Always & Usually & Sometimes & Rarely & Never & $\begin{array}{l}\text { I have not } \\
\text { ridden a bike } \\
\text { in the last year }\end{array}$ & $\begin{array}{l}\text { I do not } \\
\text { ride at } \\
\text { night }\end{array}$ & Missing & Total \\
\hline $\begin{array}{l}\text { How often do you wear a helmet while } \\
\text { biking? }\end{array}$ & $\begin{array}{r}356 \\
(78 \%)\end{array}$ & $\begin{array}{r}49 \\
(11 \%)\end{array}$ & $\begin{array}{r}10 \\
(2 \%)\end{array}$ & $\begin{array}{r}5 \\
(1 \%)\end{array}$ & $\begin{array}{r}10 \\
(2 \%)\end{array}$ & $\begin{array}{r}29 \\
(6 \%)\end{array}$ & $\mathrm{N} / \mathrm{A}$ & $\begin{array}{r}0 \\
(0 \%)\end{array}$ & 459 \\
\hline $\begin{array}{l}\text { How often do you use lights on your } \\
\text { bike during the day? }\end{array}$ & $\begin{array}{r}87 \\
(19 \%)\end{array}$ & $\begin{array}{r}61 \\
(13 \%)\end{array}$ & $\begin{array}{r}98 \\
(21 \%)\end{array}$ & $\begin{array}{r}89 \\
(19 \%)\end{array}$ & $\begin{array}{r}93 \\
(20 \%)\end{array}$ & $\begin{array}{r}29 \\
(6 \%)\end{array}$ & N/A & $\begin{array}{r}2 \\
(0 \%)\end{array}$ & 459 \\
\hline $\begin{array}{l}\text { How often do you wear reflective } \\
\text { clothing while biking at night? }\end{array}$ & $\begin{array}{r}143 \\
(31 \%)\end{array}$ & $\begin{array}{r}84 \\
(18 \%)\end{array}$ & $\begin{array}{r}68 \\
(15 \%) \\
\end{array}$ & $\begin{array}{r}36 \\
(8 \%)\end{array}$ & $\begin{array}{r}23 \\
(5 \%)\end{array}$ & $\begin{array}{r}29 \\
(6 \%)\end{array}$ & $\begin{array}{r}71 \\
(15 \%) \\
\end{array}$ & $\begin{array}{r}5 \\
(1 \%)\end{array}$ & 459 \\
\hline $\begin{array}{l}\text { How often do you use lights on your } \\
\text { bike at night? }\end{array}$ & $\begin{array}{r}319 \\
(69 \%)\end{array}$ & $\begin{array}{r}19 \\
(4 \%)\end{array}$ & $\begin{array}{r}5 \\
(1 \%)\end{array}$ & $\begin{array}{r}4 \\
(1 \%)\end{array}$ & $\begin{array}{r}5 \\
(1 \%)\end{array}$ & $\begin{array}{r}29 \\
(6 \%)\end{array}$ & $\begin{array}{r}75 \\
(16 \%)\end{array}$ & $\begin{array}{r}3 \\
(1 \%)\end{array}$ & 459 \\
\hline Question & Always & Usually & Sometimes & Rarely & Never & $\begin{array}{l}\text { I have not } \\
\text { ridden a bike } \\
\text { in the last year }\end{array}$ & $\begin{array}{l}\text { I do not } \\
\text { ride at } \\
\text { night }\end{array}$ & Missing & Total \\
\hline $\begin{array}{l}\text { When drivers pass you, they are at least } \\
\text { three feet to the left of your bicycle. }\end{array}$ & $\begin{array}{r}4 \\
(1 \%)\end{array}$ & $\begin{array}{r}202 \\
(44 \%)\end{array}$ & $\begin{array}{r}185 \\
(40 \%)\end{array}$ & $\begin{array}{r}37 \\
(8 \%)\end{array}$ & $\begin{array}{r}2 \\
(0 \%)\end{array}$ & $\begin{array}{r}29 \\
(6 \%)\end{array}$ & $\mathrm{N} / \mathrm{A}$ & $\begin{array}{r}0 \\
(0 \%)\end{array}$ & 459 \\
\hline Drivers pass you too closely & $\begin{array}{r}11 \\
(2 \%)\end{array}$ & $\begin{array}{r}71 \\
(15 \%)\end{array}$ & $\begin{array}{r}269 \\
(59 \%)\end{array}$ & $\begin{array}{r}77 \\
(17 \%)\end{array}$ & $\begin{array}{r}2 \\
(0 \%)\end{array}$ & $\begin{array}{r}29 \\
(6 \%)\end{array}$ & $\mathrm{N} / \mathrm{A}$ & $\begin{array}{r}0 \\
(0 \%\end{array}$ & 459 \\
\hline $\begin{array}{l}\text { Drivers are aggressive or hostile } \\
\text { towards you }\end{array}$ & $\begin{array}{r}5 \\
(1 \%)\end{array}$ & $\begin{array}{r}23 \\
(5 \%)\end{array}$ & $\begin{array}{r}178 \\
(39 \%)\end{array}$ & $\begin{array}{r}203 \\
(44 \%)\end{array}$ & $\begin{array}{r}21 \\
(5 \%)\end{array}$ & $\begin{array}{r}29 \\
(6 \%)\end{array}$ & $\mathrm{N} / \mathrm{A}$ & $\begin{array}{r}0 \\
(0 \%)\end{array}$ & 459 \\
\hline $\begin{array}{l}\text { When you approach a stop sign on a } \\
\text { bicycle, you stop. }\end{array}$ & $\begin{array}{r}92 \\
(20 \%)\end{array}$ & $\begin{array}{r}205 \\
(45 \%)\end{array}$ & $\begin{array}{r}109 \\
(24 \%)\end{array}$ & $\begin{array}{r}23 \\
(5 \%)\end{array}$ & $\begin{array}{r}1 \\
(0 \%)\end{array}$ & $\begin{array}{r}29 \\
(6 \%)\end{array}$ & N/A & $\begin{array}{r}0 \\
10 \%\end{array}$ & 459 \\
\hline $\begin{array}{l}\text { When you approach a red light at a } \\
\text { traffic signal on a bicycle, you stop. }\end{array}$ & $\begin{array}{r}338 \\
(74 \%)\end{array}$ & $\begin{array}{r}82 \\
(18 \%)\end{array}$ & $\begin{array}{r}10 \\
(2 \%)\end{array}$ & $\begin{array}{r}0 \\
(0 \%)\end{array}$ & $\begin{array}{r}0 \\
(0 \%)\end{array}$ & $\begin{array}{r}29 \\
(6 \%)\end{array}$ & N/A & $\begin{array}{r}0 \\
(0 \%)\end{array}$ & 459 \\
\hline $\begin{array}{l}\text { You ride your bicycle on the } \\
\text { appropriate side of the road with the } \\
\text { flow of traffic. }\end{array}$ & $\begin{array}{r}395 \\
(86 \%)\end{array}$ & $\begin{array}{r}28 \\
(6 \%)\end{array}$ & $\begin{array}{r}3 \\
(1 \%)\end{array}$ & $\begin{array}{r}2 \\
(0 \%)\end{array}$ & $\begin{array}{r}2 \\
(0 \%)\end{array}$ & $\begin{array}{r}29 \\
(6 \%)\end{array}$ & N/A & $\begin{array}{r}0 \\
10 \%\end{array}$ & 459 \\
\hline Question & Always & Usually & Sometimes & Rarely & Never & $\begin{array}{l}\text { I have not } \\
\text { driven a motor } \\
\text { vehicle in the } \\
\text { last year }\end{array}$ & $\begin{array}{l}\text { I do not } \\
\text { ride at } \\
\text { night }\end{array}$ & Missing & Total \\
\hline $\begin{array}{l}\text { I pass bicyclists at least three feet to } \\
\text { the left of the bicycle }\end{array}$ & $\begin{array}{r}377 \\
(82 \%)\end{array}$ & $\begin{array}{r}62 \\
(14 \%)\end{array}$ & $\begin{array}{r}3 \\
(1 \%)\end{array}$ & $\begin{array}{r}4 \\
(1 \%)\end{array}$ & $\begin{array}{r}1 \\
(0 \%)\end{array}$ & $\begin{array}{r}12 \\
(3 \%)\end{array}$ & N/A & $\begin{array}{r}0 \\
(0 \%)\end{array}$ & 459 \\
\hline $\begin{array}{l}\text { I pass bicyclists within three feet of the } \\
\text { bicycle }\end{array}$ & $\begin{array}{r}47 \\
(10 \%)\end{array}$ & $\begin{array}{r}9 \\
(2 \%)\end{array}$ & $\begin{array}{r}21 \\
(5 \%)\end{array}$ & $\begin{array}{r}91 \\
(20 \%)\end{array}$ & $\begin{array}{r}279 \\
(61 \%)\end{array}$ & $\begin{array}{r}12 \\
(3 \%)\end{array}$ & N/A & $\begin{array}{r}0 \\
(0 \%)\end{array}$ & 459 \\
\hline $\begin{array}{l}\text { Bicyclists act aggressively when I am } \\
\text { driving }\end{array}$ & $\begin{array}{r}2 \\
(0 \%)\end{array}$ & $\begin{array}{r}10 \\
(2 \%)\end{array}$ & $\begin{array}{r}60 \\
(13 \%)\end{array}$ & $\begin{array}{r}196 \\
(43 \%)\end{array}$ & $\begin{array}{r}179 \\
(39 \%)\end{array}$ & $\begin{array}{r}12 \\
(3 \%)\end{array}$ & $\mathrm{N} / \mathrm{A}$ & $\begin{array}{r}0 \\
(0 \%)\end{array}$ & 459 \\
\hline Question & $\begin{array}{r}\text { Strongly } \\
\text { Agree }\end{array}$ & $\begin{array}{r}\text { Somewhat } \\
\text { Agree }\end{array}$ & $\begin{array}{r}\text { Neither } \\
\text { Agree nor } \\
\text { Disagree }\end{array}$ & $\begin{array}{r}\text { Somewhat } \\
\text { Disagree }\end{array}$ & $\begin{array}{l}\text { Strongly } \\
\text { Disagree }\end{array}$ & $\begin{array}{r}\text { I have not } \\
\text { driven a motor } \\
\text { vehicle in the } \\
\text { last year }\end{array}$ & $\begin{array}{r}\text { I do not } \\
\text { ride at } \\
\text { night }\end{array}$ & Missing & Total \\
\hline $\begin{array}{l}\text { I feel safe riding a bike in a dedicated } \\
\text { bike lane }\end{array}$ & $\begin{array}{r}184 \\
(40 \%)\end{array}$ & $\begin{array}{r}211 \\
(46 \%)\end{array}$ & $\begin{array}{r}25 \\
(5 \%)\end{array}$ & $\begin{array}{r}34 \\
(7 \%)\end{array}$ & $\begin{array}{r}3 \\
(1 \%)\end{array}$ & $\mathrm{N} / \mathrm{A}$ & N/A & $\begin{array}{r}2 \\
(0 \%)\end{array}$ & 459 \\
\hline $\begin{array}{l}\text { I feel safe sharing the road with cars } \\
\text { when I bike. }\end{array}$ & $\begin{array}{r}41 \\
(9 \%)\end{array}$ & $\begin{array}{r}211 \\
(46 \%)\end{array}$ & $\begin{array}{r}57 \\
(12 \%)\end{array}$ & $\begin{array}{r}111 \\
(24 \%)\end{array}$ & $\begin{array}{r}37 \\
(8 \%)\end{array}$ & N/A & N/A & $\begin{array}{r}2 \\
(0 \%)\end{array}$ & 459 \\
\hline I feel safe riding a bike on a sidewalk & $\begin{array}{r}58 \\
(13 \%) \\
\end{array}$ & $\begin{array}{r}77 \\
(17 \%) \\
\end{array}$ & $\begin{array}{r}74 \\
(16 \%) \\
\end{array}$ & $\begin{array}{r}134 \\
(29 \%) \\
\end{array}$ & $\begin{array}{r}113 \\
(25 \%) \\
\end{array}$ & N/A & $\mathrm{N} / \mathrm{A}$ & $\begin{array}{r}3 \\
(1 \%) \\
\end{array}$ & 459 \\
\hline I feel safe riding a bike around curves & $\begin{array}{r}156 \\
(34 \%)\end{array}$ & $\begin{array}{r}177 \\
(39 \%)\end{array}$ & $\begin{array}{r}68 \\
(15 \%)\end{array}$ & $\begin{array}{r}42 \\
(9 \%)\end{array}$ & $\begin{array}{r}14 \\
(3 \%)\end{array}$ & N/A & N/A & $\begin{array}{r}2 \\
(0 \%)\end{array}$ & 459 \\
\hline
\end{tabular}




\begin{tabular}{|c|c|c|c|c|c|c|c|c|c|}
\hline I feel safe riding a bike on hills & $\begin{array}{r}188 \\
(41 \%)\end{array}$ & $\begin{array}{r}168 \\
(37 \%) \\
\end{array}$ & $\begin{array}{r}63 \\
(14 \%) \\
\end{array}$ & $\begin{array}{r}30 \\
(7 \%) \\
\end{array}$ & $\begin{array}{r}7 \\
(2 \%) \\
\end{array}$ & $\mathrm{N} / \mathrm{A}$ & $\mathrm{N} / \mathrm{A}$ & $\begin{array}{r}3 \\
(1 \%) \\
\end{array}$ & 459 \\
\hline $\begin{array}{l}\text { I know how to maneuver most road } \\
\text { intersections on a bike. }\end{array}$ & $\begin{array}{r}294 \\
(64 \%) \\
\end{array}$ & $\begin{array}{r}123 \\
(27 \%) \\
\end{array}$ & $\begin{array}{r}21 \\
(5 \%) \\
\end{array}$ & $\begin{array}{r}10 \\
(2 \%) \\
\end{array}$ & $\begin{array}{r}9 \\
(2 \%) \\
\end{array}$ & $\mathrm{N} / \mathrm{A}$ & $\mathrm{N} / \mathrm{A}$ & $\begin{array}{r}2 \\
(0 \%) \\
\end{array}$ & 459 \\
\hline $\begin{array}{l}\text { There are enough bike lanes where I } \\
\text { want to bike }\end{array}$ & $\begin{array}{r}19 \\
(4 \%)\end{array}$ & $\begin{array}{r}59 \\
(13 \%)\end{array}$ & $\begin{array}{r}58 \\
(13 \%)\end{array}$ & $\begin{array}{r}109 \\
(24 \%)\end{array}$ & $\begin{array}{r}212 \\
(46 \%)\end{array}$ & $\mathrm{N} / \mathrm{A}$ & $\mathrm{N} / \mathrm{A}$ & $\begin{array}{r}2 \\
(0 \%)\end{array}$ & 459 \\
\hline $\begin{array}{l}\text { I worry about being involved in a } \\
\text { bicycle crash on the road. }\end{array}$ & $\begin{array}{r}129 \\
(28 \%)\end{array}$ & $\begin{array}{r}199 \\
(43 \%)\end{array}$ & $\begin{array}{r}67 \\
(15 \%)\end{array}$ & $\begin{array}{r}47 \\
(10 \%)\end{array}$ & $\begin{array}{r}15 \\
(3 \%)\end{array}$ & $\mathrm{N} / \mathrm{A}$ & $\mathrm{N} / \mathrm{A}$ & $\begin{array}{r}0 \\
(0 \%)\end{array}$ & 459 \\
\hline $\begin{array}{l}\text { Bicycling under the influence of alcohol } \\
\text { should be illegal. }\end{array}$ & $\begin{array}{r}248 \\
(54 \%)\end{array}$ & $\begin{array}{r}25 \\
(5 \%)\end{array}$ & $\begin{array}{r}65 \\
(14 \%)\end{array}$ & $\begin{array}{r}25 \\
(5 \%)\end{array}$ & $\begin{array}{r}24 \\
(5 \%)\end{array}$ & $\mathrm{N} / \mathrm{A}$ & $\mathrm{N} / \mathrm{A}$ & $\begin{array}{r}2 \\
(0 \%)\end{array}$ & 459 \\
\hline $\begin{array}{l}\text { Compared to human drivers, } \\
\text { automated vehicles (self-driving cars) } \\
\text { will be safer when sharing the road } \\
\text { with bicyclists. }\end{array}$ & $\begin{array}{r}68 \\
(15 \%)\end{array}$ & $\begin{array}{r}106 \\
(23 \%)\end{array}$ & $\begin{array}{r}183 \\
(40 \%)\end{array}$ & $\begin{array}{r}59 \\
(13 \%)\end{array}$ & $\begin{array}{r}41 \\
(9 \%)\end{array}$ & $\mathrm{N} / \mathrm{A}$ & $\mathrm{N} / \mathrm{A}$ & $\begin{array}{r}2 \\
(0 \%)\end{array}$ & 459 \\
\hline $\begin{array}{l}\text { If a device on your bike were developed } \\
\text { that would allow your presence to be } \\
\text { detected by nearby vehicles (to } \\
\text { increase their awareness of your } \\
\text { presence on the road), you would use } \\
\text { it. }\end{array}$ & $\begin{array}{r}209 \\
(46 \%)\end{array}$ & $\begin{array}{r}174 \\
(38 \%)\end{array}$ & $\begin{array}{r}52 \\
(11 \%)\end{array}$ & $\begin{array}{r}14 \\
(3 \%)\end{array}$ & $\begin{array}{r}8 \\
(2 \%)\end{array}$ & $\mathrm{N} / \mathrm{A}$ & $\mathrm{N} / \mathrm{A}$ & $\begin{array}{r}2 \\
(0 \%)\end{array}$ & 459 \\
\hline $\begin{array}{l}\text { You would be willing to pay a one-time } \\
\text { fee for such a device }\end{array}$ & $\begin{array}{r}160 \\
(35 \%)\end{array}$ & $\begin{array}{r}173 \\
(38 \%)\end{array}$ & $\begin{array}{r}76 \\
(17 \%)\end{array}$ & $\begin{array}{r}20 \\
(4 \%)\end{array}$ & $\begin{array}{r}28 \\
(6 \%)\end{array}$ & $\mathrm{N} / \mathrm{A}$ & $\mathrm{N} / \mathrm{A}$ & $\begin{array}{r}2 \\
(0 \%)\end{array}$ & 459 \\
\hline
\end{tabular}

\subsubsection{Safety Equipment}

The survey population we have captured has very high rates of bicycle safety equipment usage. The majority of respondents state that they always wear a helmet (78\%) and always use lights on their bikes at night (69\%). Additionally, 31\% of bicyclists always wear reflective clothing at night and $64 \%$ at least sometimes do. Additionally, a majority of the sample at least sometimes report using lights on their bike during the day, where $19 \%$ recording always, $13 \%$ usually, and $21 \%$ sometimes.

\subsubsection{Bicyclists Perceptions of Drivers}

When asked about how often the respondent is passed by an automobile at least 3 feet to the left, only $1 \%$ of respondents said always, $44 \%$ said usually and $40 \%$ said sometimes. Similarly, when asked if automobile drivers pass them too closely, the majority of respondents (59\%) said sometimes. These statistics tell us that with regularity bicyclists feel that automobiles are passing them without giving the 3 feet passing space required by the Code of Virginia (Title 46.2, 2014). This may be because the driver does not know the law, does not want to comply, or in fact is giving 3 feet but to the bicyclist it feels too close. Regardless of the reason, if the law is not well followed or if it does not feel like enough space to the bicyclist, when the bicyclist is uncomfortable it discourages riding. These statistics speak to the need for separation between cars and bicycles on the road as well as better education about laws relating to bicyclists.

\subsubsection{Bicyclists Behavior on the Road}

When looking at how bicyclists follow the rules of the road, only $20 \%$ of bicyclists state that they always stop at stop signs, $74 \%$ say that they always stop at red traffic lights, and $86 \%$ say that they always ride on the correct side of the road. There are differing opinions about the best way for bicyclists to deal with these types of traffic control elements, however, bicyclists are required to stop at stop signs and traffic lights with some exceptions. Two of these exceptions are the "Idaho stop" law, and "dead reds". The Idaho bicycle laws were enacted in the state in 1982 and essentially allow bicyclists to treat stop signs as yield signs, and traffic lights as stop signs (McLeod, 2013). Laws such as "dead reds" refer to the problem with 
traffic signals that do not detect bicyclists and resultantly will not turn green for the bicyclist. These laws allow bicyclists to proceed legally through the red light, yielding to any traffic. Virginia has a "dead red" law, where bicyclists (also mopeds and motorcyclists) are allowed to proceed through a red light after coming to a full stop for two complete light cycles or two minutes (whichever is shorter), exercising care, treating the traffic control as a stop sign, determining it is safe to move through the intersection, and yielding right of way to other vehicles. After following this procedure, bicyclists are able to legally ride through a red light (Title 46.2, 2013). These types of laws are designed to make up for traffic devices that do not detect bicyclists, and to accommodate the needs of bicyclists being different from cars. These laws may shine a light on why in our survey only $20 \%$ of bicyclists reported always stopping at stop signs. A number of comments on our survey discussed the use of Idaho stop laws or listed some safety benefits of not stopping at stop signs, particularly when in a group or moving fast. These issues remain up for debate, as some argue that bicyclists are safest when they follow the same rules as automobile drivers, "same rules, same road" and that Idaho stops undermine this ideology (McLeod, 2013). Despite their persistence for 30 years, "Idaho stop" laws have yet to be readily expanded to other states, whether they eventually will become more accepted nationwide remains to be seen.

\subsubsection{Drivers Perceptions of Bicyclists}

The survey respondents when asked about how they deal with bicyclists on the road as drivers described themselves as obeying the 3-foot clearance law much more often than when other drivers pass them as bicyclists. $82 \%$ of respondents said they always give the 3 feet of clearance, compared to stating that $1 \%$ of drivers always give 3 feet of clearance when they are biking. This discrepancy may be somewhat explained by the fact that our survey respondent base consists mostly of active bikers, who may be more cognizant of how they treat other bikers on the road. Additionally, it may be explained by perception, if three feet does not feel sufficient from the bikers' perspective, they may think the automobile is too close even when complying by the law.

\subsubsection{Bicyclists Perception of Road Safety}

When the respondents were asked if they feel safe in dedicated bike lanes or sharing the road with cars the majority of people agreed. Most people agree with the statements that they "worry about being involved in a bicycle crash on the road" and that "bicycling under the influence should be illegal" In the state of Virginia bicycling under the influence is illegal, which the majority of respondents stated that they were aware of, so these responses may be influenced by an agreement with the current law or from safety concerns. We also posed some questions based on the results from the Virginia police crash report dataset, including how safe people feel on hills, curves, and if they know how to move through intersections. Most people reported that they do feel safe on these road elements and know how to maneuver most intersections. The overwhelming majority of people reported that they agree they would use a device that would alert nearby cars to their presence. Fewer people agreed they would pay for it, but still a majority would.

TABLE 6 Descriptive statistics for survey questions with binary responses.

\begin{tabular}{|l|r|r|r|r|r|}
\hline Question & \multicolumn{1}{|l|}{ Yes } & Percent Yes & No & Percent No & \multicolumn{1}{l|}{ Total } \\
\hline In the past week have you used a bike? & 371 & $81 \%$ & 88 & $19 \%$ & 459 \\
\hline $\begin{array}{l}\text { In the past week have you walked for } \\
\text { recreation or exercise? }\end{array}$ & 358 & $78 \%$ & 101 & $22 \%$ & 459 \\
\hline In the past week did you use public transit & 81 & $18 \%$ & 378 & $82 \%$ & 459 \\
\hline $\begin{array}{l}\text { In the past week were you a driver or } \\
\text { passenger in an automobile? }\end{array}$ & 437 & $95 \%$ & 22 & $5 \%$ & 459 \\
\hline Do you participate in a bikeshare program? & 40 & $9 \%$ & 419 & $91 \%$ & 459 \\
\hline Do you use an electric bike? & 8 & $2 \%$ & 451 & $98 \%$ & 459 \\
\hline
\end{tabular}




\begin{tabular}{|l|r|r|r|r|r|}
\hline Have you used a bike in the past year? & 430 & $94 \%$ & 29 & $6 \%$ & 459 \\
\hline $\begin{array}{l}\text { Do you know who among Virginia cyclists } \\
\text { are required to wear helmets? }\end{array}$ & 304 & $66 \%$ & 155 & $34 \%$ & 459 \\
\hline $\begin{array}{l}\text { Are you aware of when Virginia bicyclists are } \\
\text { required to use headlights and reflectors? }\end{array}$ & 283 & $62 \%$ & 176 & $38 \%$ & 459 \\
\hline $\begin{array}{l}\text { Do you know how the driving under the } \\
\text { influence law in Virginia applies to bicyclists? }\end{array}$ & 272 & $59 \%$ & 187 & $41 \%$ & 459 \\
\hline $\begin{array}{l}\text { Are you aware of how bicyclists are required } \\
\text { to behave at stop signs and traffic lights? }\end{array}$ & 428 & $93 \%$ & 31 & $7 \%$ & 459 \\
\hline
\end{tabular}

\subsubsection{Travel Patterns}

The majority of the respondents state that in the past week they have biked $(81 \%)$, walked $(78 \%)$, and been a driver or passenger in an automobile (95\%). Far fewer people reported using transit (18\%), bikeshare $(9 \%)$ or an electric bike $(2 \%)$.

\subsubsection{Bicycle Laws}

In the survey we asked questions about whether or not respondents know some Virginia bicycling laws including who needs to wear a helmet, when to use headlights and reflectors, what the bicycling under the influence law is, and how to behave at stop signs and traffic lights. And all cases, more people reported knowing the laws than did not, and in the case of how to behave at stop signs and lights, almost everyone (93\%) knew the law. However, the number of yes responses for the other three (helmets (66\%), headlights/reflectors (62\%), and BUI laws (59\%)) were far fewer, which based on our sample size of mostly active bicyclists, we may have expected to be much higher. We would expect a population of more casual riders or non-bicyclists to have even less knowledge on these laws. Furthermore, the way these questions were phrased did not require the respondent to give the laws or choose a correct answer, they self-admitted to not knowing the laws rather than getting an answer incorrect. Because of this we cannot discern from the people who stated they knew the law, whether they were actually correct. We would expect that some of the yes answers may actually be nos. In summary, our sampling is likely an overrepresentation of people who know the bicycling laws, nevertheless the statistics do not show high levels of knowledge. These questions speak to the need for better education on what bicyclists are supposed to do on the road, for both bicyclists and drivers, so that everyone has the same expectations for how bikers will behave to improve understanding and safety.

\subsection{METHODOLOGY}

\subsubsection{Basic Statistics}

Standard exploratory data analysis tools were utilized in this study to initially analyze the myriad data that were acquired in the survey. Histograms and bar graphs were among the visual tools used on questions to visually inspect the distribution of the data and check for outliers or errors. Additionally, data summary statistics such as response counts, means, medians, and ranges were used to understand the types of answers we were receiving and how to proceed with further modeling techniques.

\subsubsection{Models}

\subsubsection{Binary Logistic Regression}

A binary logistic regression is utilized in the statistical analysis to analyze some of the survey questions which have binary outcomes. For example, the questions asking the respondent whether they know the laws that apply to Virginia bicyclists where the outcome is a yes or no response. Binary logistic regression is useful in these types of cases because it is used to predict the probability of a binary outcome based upon a number of continuous or categorical variables. The equation for a binary logistic regression 
can be written as follows, where $\mathrm{Y}$ is the binary dependent variable and $Y=0$ or 1 . $X$ represents predictor values, or the independent variables in the equation, and $\beta$ are regression parameters determined by running the model. $X \beta$ represent a vector of predictor values and regression parameters $\beta_{0}+\beta_{1} X_{1}+\beta_{2} X_{2}+\cdots+$ $\beta_{K} X_{K}$ (Harrell, 2015).

$$
\operatorname{Prob}\{Y=1 \mid X\}=[1+\exp (-X \beta)]^{-1}
$$

\subsubsection{Assumptions of the binary logistic regression}

The dependent variable used in a binary logistic regression must be dichotomous, all of the variables we used in this analysis had binary responses. One or more independent variables must be continuous or categorical. The dependent variable has mutually exclusive and exhaustive categories. There also must be independence of observations which is true in the case of our data as each observation is from an independent respondent. Finally, there must be a linear relationship between any continuous variables and the logit transformation of the dependent variable. To test this assumption an interaction term was entered into the model for each continuous variable that consisted of the variable multiplied by its natural logarithm. If this variable is significant, this assumption is violated (Laerd Statistics Binomial, 2013).

\subsubsection{Poisson Regression}

The Poisson regression model is used to in statistical analyses to examine count data and determine independent variables, both continuous and categorical, that affect the probability of a certain outcome. A dependent variable $Y$ is assumed to follow a Poisson distribution where the possible values of $Y$ are nonnegative integer values. Regressor variables, the $X$ 's, and the regression coefficients, $\beta$ 's, determine the poisson incidence rate $\mu$ which defines the likelihood of an event occurring. $\mu$ can be defined as follows (Regression Analysis, 2017):

$$
\mu=t \exp \left(\beta_{1} X_{1}+\beta_{2} X_{2}+\cdots+\beta_{K} X_{K}\right)
$$

And the Poisson regression model for an observation i is shown below (Regression Analysis, 2017):

$$
\operatorname{Prob}\left\{Y_{i}=y_{i} \mid \mu_{i}, t_{i}\right\}=\frac{e^{-\mu_{i} t_{i}}\left(\mu_{i} t_{i}\right)^{y_{i}}}{y_{i} !}
$$

\subsubsection{Assumptions of the Poisson Regression}

In order for data to be modeled using the Poisson distribution there are a few assumptions that must be satisfied in order for the results to be valid. First, the response variable must be count data and the independent variables must be continuous, ordinal, or categorical data. Additionally, there should be independence of observations, the dependent variable counts follow a Poisson distribution, and the mean and variance of the model are the same (Laerd Statistics Poisson, 2013).

\subsubsection{Negative Binomial Regression}

The negative binomial distribution, like the Poisson distribution, is used to examine a dependent variable that is in the form of count data based on a number of continuous and categorical independent variables. The difference between the Poisson and the Negative binomial is that the latter incorporates an over dispersion parameter, whereas the Poisson model must represent data with a mean equal to its variance (Greene, 2008).

$$
\begin{aligned}
\operatorname{Prob}\left(Y=y_{i} \mid x_{i}\right) & =\frac{\Gamma\left(\theta+y_{i}\right)}{\Gamma\left(y_{i}+1\right) \Gamma(\theta)} r_{i}^{y_{i}}\left(1-r_{i}\right)^{\theta} \\
\lambda_{i} & =\exp \left(x_{i}^{\prime} \beta\right) \\
r_{i} & =\lambda_{i} /\left(\theta+\lambda_{i}\right)
\end{aligned}
$$




\subsubsection{Assumptions Negative Binomial Regression}

The negative binomial regression has similar assumptions to the Poisson regression, but relaxes the requirement that the mean and variance of the model are the same.

\subsubsection{Multinomial Logit Model}

The MNL model is implemented in transportation studies to analyze discrete outcome categories. In this research, the response variable may represent the five likert value choices for a survey question: never (1)

, rarely (2), sometimes (3), usually (4), and always (5). Various attitude, behavioral, knowledge, and demographic variables are the dependent variables in the model, to predict the survey question outcome. The probability of a respondent choosing a certain response $\mathrm{j}$ is represented by the following equation (Greene, 2008):

$$
\operatorname{Prob}\left(Y_{i}=j \mid w_{i}\right)=\frac{\exp \left(w_{i}^{\prime} \alpha_{j}\right)}{\sum_{j=1}^{5} \exp \left(w_{i}^{\prime} \alpha_{j}\right)}, j=1,2,3,4,5
$$

Where $\mathrm{w}_{\mathrm{i}}$ are characteristics and $\alpha_{j}$ are estimated coefficients. The $\alpha_{j}$ coefficients vary for each response level allowing the flexibility of a characteristic having effects in both directions on the likelihood of a respondent choosing a particular response. Additionally, the coefficients themselves cannot solely be used to interpret the effect of a characteristic as the actual effect may not be the same as the sign of the coefficient. To analyze the true effects, marginal effects must be calculated using the following formula (Greene, 2008):

$$
\delta_{i j}=\frac{\partial P_{i j}}{\partial W_{i}}=P_{i j}\left[\alpha_{j}-\sum_{k=0}^{J} P_{i k} \alpha_{k}\right]=P_{i j}\left[\alpha_{j}-\bar{\alpha}\right]
$$

The marginal effects equation is found by differentiating equation 15 . Where $P_{i j}$ is the probability of a crash with i characteristics falling in the injury severity category $\mathrm{j}$ and is calculated using equation 18.

\subsubsection{Assumptions of the MNL model}

For the multinomial logit model to be used justifiably it must be ensured that the data meet the assumptions of the model. First, the dependent variable should be nominal data and the independent variables should be continuous, ordinal, or nominal. Furthermore, there should be independence of observations, no multicollinearity, and there should be a linear relationship between any continuous independent variables and the logit transformation of the dependent variable (Laerd Statistics Multinomial, 2013).

\subsection{RESULTS AND CONCLUSIONS}

\subsubsection{Basic Statistics}

As previously mentioned, one reason for undertaking data collection using a survey was to capture more information about unreported bicycle crashes. Based on the previous work on police reported crashes we suspected that there was high underreporting of bicycle crashes, particularly of minor and no injury crashes. This phenomenon has been documented and some of the initial data analysis work on this survey revealed validated our suspicions. Figure 2 below summarizes information collected using the survey about three different types of crashes, those that are solo bike crashes where no other bike or automobile is involved, those that involve bikes crashing with other bikes, and those that involve bikes crashing with other automobiles. In the case that a crash involved multiple bikes and a car, or a bike and multiple cars it 
was considered to be a bike vs automobile crash, as we believe any crash involving an automobile, regardless of the number of bikes is likely dominated by the more powerful interaction of the car hitting the bicyclists rather than the bicyclists hitting each other. This cross tabulation shows that only 44 of the 412 crashes documented in the survey were reported to the police. This represents $12 \%$ of the data. This is a much smaller amount than was expected based on previous literature on underreporting of bicycle crashes. These results highlight to us the importance of seeking crash data from other sources in addition to police reported crash data, however the value of police crash reported data is still apparent as they tend to capture more severe and fatal crashes involving cars. Police report data is still useful in understanding dangerous interactions between bikes and cars, but figure 2 highlights its limitations.

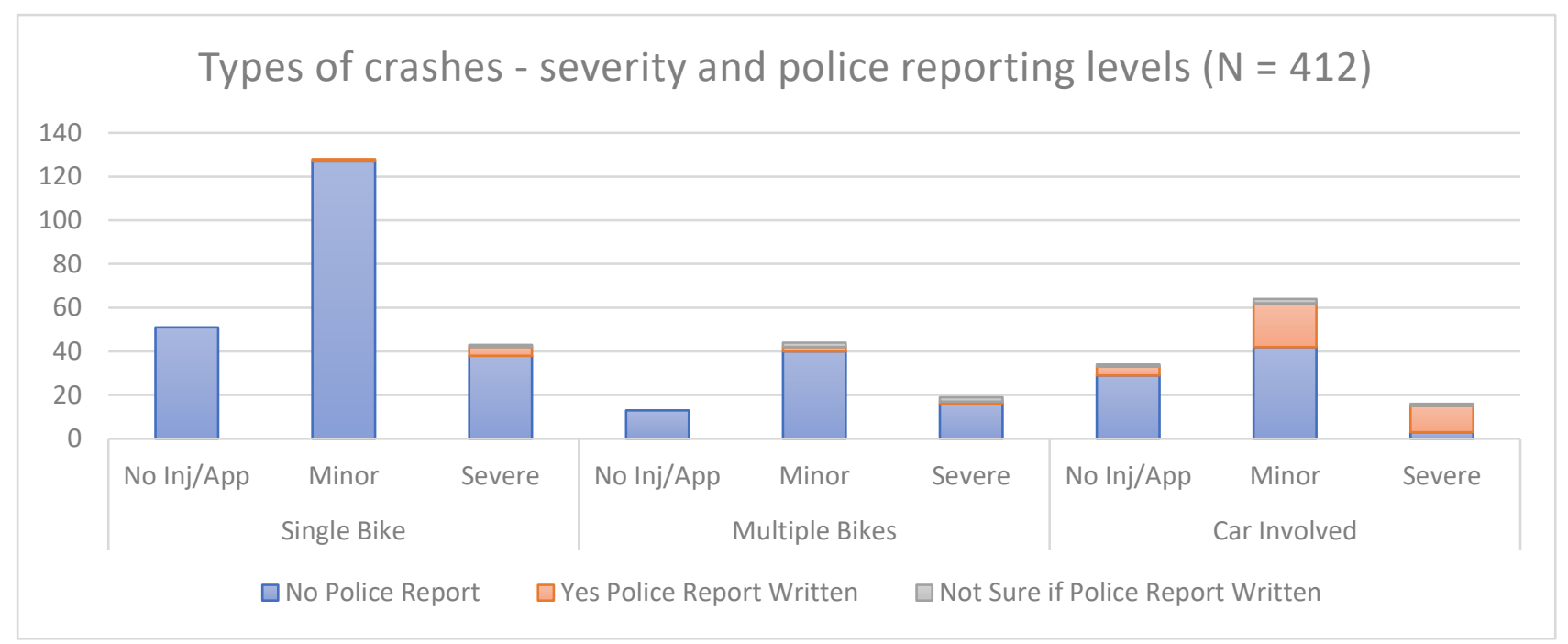

FIGURE 2 Types of bicycle crashes with severity and reporting levels.

\subsubsection{Binary Logistic Regression}

\subsubsection{Stop Sign and Traffic Light Laws}

A binomial logistic regression model was used to determine if there are variables that influence the likelihood that a respondent stated that they know how Virginia cyclists are required to behave at stop signs and traffic lights. A test of the full model versus one with intercept only was found to be statistically significant using the Omnibus test, $\mathrm{X}^{2}(9, \mathrm{~N}=414)=85.035, \mathrm{p}<0.000$, with a Nagelkerke $\mathrm{R}^{2}$ value of 0.466 People who participate in bikeshare are 0.109 times less likely to know the stop sign and signal laws than people who do not. This relationship is statistically significant, but our pool of bikeshare users is fairly small. Additionally, those that describe themselves as strong and fearless or enthused and confident bikers compared to those who are interested but concerned are much more likely to know how to behave at stop signs and traffic lights. This indicates a correlation between confidence and knowledge of bicycling laws. Furthermore, respondents who wear reflective clothing at any rate (always, usually, rarely) compared to never are much more likely to know how to behave at stop signs and traffic lights. These last two factors, confidence and use of reflective clothing are likely capturing a level of exposure that is not being incorporated into the model. Experienced bikers are the ones that will be confident, utilize safety measures, and know the biking laws.

TABLE 7 Model results for binomial logistic regression of knowledge of Virginia's stop sign and traffic light laws.

\begin{tabular}{|l|l|l|l|l|}
\hline Variables & B & S.E. & Sig. & $\operatorname{Exp}(B)$ \\
\hline
\end{tabular}




\begin{tabular}{|l|r|r|r|r|}
\hline Bikeshare Use & -2.215 & .813 & .006 & .109 \\
\hline Bike Attitude Strong & 4.969 & .876 & .000 & 143.819 \\
\hline Bike Attitude Enthused & 3.795 & .729 & .000 & 44.461 \\
\hline Reflective Always & 3.845 & 1.204 & .001 & 46.746 \\
\hline Reflective Usually & 5.002 & 1.170 & .000 & 148.778 \\
\hline Reflective Sometimes & .677 & .614 & .270 & 1.968 \\
\hline Reflective Rarely & 3.484 & 1.366 & .011 & 32.599 \\
\hline $\begin{array}{l}\text { Education (some high school, high } \\
\text { school, some college, associates) }\end{array}$ & 1.616 & .709 & .023 & 5.032 \\
\hline Education (bachelors) & & & & \\
\hline Constant & -2.886 & 1.026 & .005 & .056 \\
\hline
\end{tabular}

\subsubsection{Poisson and Negative Binomial}

\subsubsection{Total Number of Crashes}

Count models are utilized in this analysis to examine various characteristic that may affect the number of bicycle crashes a person is likely to be involved in. Standard count models such as Poisson, negative binomial, zero inflated, and ordinary least squares were considered for this analysis. The use of ordinary least squares was initially ruled out because it is often problematic when using data with zeros if the data is log transformed. As our data involves many cases where the respondent has been in zero crashes, this modeling approach was deemed not a good fit. The assumptions for a Poisson model have been discussed above. A histogram showing the distribution of the dependent variable can be seen in Figure 3.

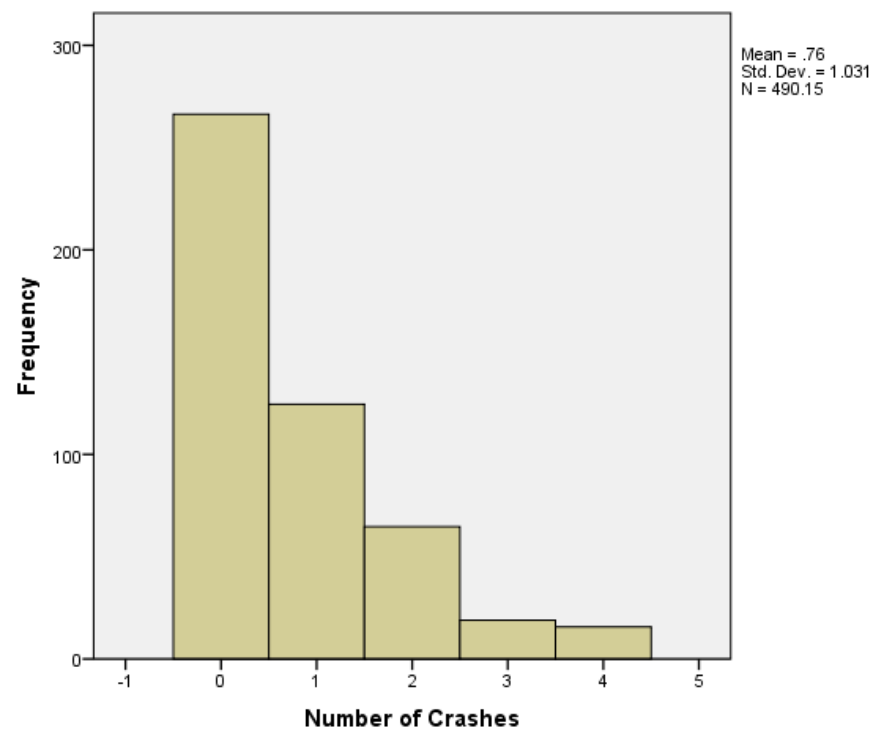

FIGURE 3 Histogram of respondent number of crashes.

This dataset is over dispersed with a variance greater than the mean. However, as the variance was not very much higher, we chose to pursue a Poisson model initially. The results of this model may be seen in table 11 . 
TABLE 8 Model results from Poisson count model of number of bicycle crashes a person is involved in.

\begin{tabular}{|l|l|l|l|l|}
\hline Variables & IRR & $\begin{array}{l}\text { Robust Std. } \\
\text { Err. }\end{array}$ & $\mathrm{Z}$ & $\mathrm{P}>|\mathrm{z}|$ \\
\hline Bike Attitude Strong & 3.365 & 1.644 & 2.48 & 0.013 \\
\hline Bike Attitude Enthused & 3.197 & 1.564 & 2.37 & 0.018 \\
\hline Bike Attitude Interested & 1 & Omitted & & \\
\hline Bike Attitude No Way & 1 & Omitted & & \\
\hline Day Lights Always & 2.391 & 0.945 & 2.21 & 0.027 \\
\hline Day Lights Usually & 1.220 & 0.406 & 0.60 & 0.550 \\
\hline Day Lights Sometimes & 1.347 & 0.465 & 0.86 & 0.388 \\
\hline Day Lights Rarely & 1.075 & 0.391 & 0.20 & 0.843 \\
\hline Day Lights Never & 1 & Omitted & & \\
\hline Night Lights Always & 0.867 & 0.429 & -0.29 & 0.773 \\
\hline Night Lights Usually & 0.811 & 0.432 & -0.39 & 0.695 \\
\hline Night Lights Sometimes & 0.533 & 0.696 & -0.48 & 0.630 \\
\hline Night Lights Rarely & 4.533 & 2.838 & 2.41 & 0.016 \\
\hline Night Lights Never & 1 & Omitted & & \\
\hline Stop Traffic Signals Always & 0.581 & 0.219 & -1.44 & 0.149 \\
\hline Stop Traffic Signals Usually & 0.433 & 0.185 & -1.96 & 0.050 \\
\hline Stop Traffic Signals Sometimes & 1 & Omitted & & \\
\hline Stop Traffic Signals Rarely & 1 & Omitted & & \\
\hline Stop Traffic Signals Never & 1 & Omitted & & \\
\hline Knowledge Helmet Law & 2.490 & 0.794 & 2.86 & 0.004 \\
\hline Constant & 0.197 & 0.111 & -2.88 & 0.004 \\
\hline
\end{tabular}

However, a goodness of fit chi squared test of the Poisson model is statistically significant, indicating that Poisson regression is not a good fit for the data. As the variance of the data is higher than the mean, the negative binomial regression is then used to model the data. The results of this effort show the alpha value, which models the over dispersion in the data, is greater than zero. This indicates over dispersion is present enough that negative binomial may be a better modeling choice. Additionally, Ordinary least squares versions of Poisson and negative binomial models were tested but did not converge. We may suspect that our data does not truly fit the definition of zero inflated data where there are "true zeroes" and "excess zeroes". The results of the negative binomial regression may be seen in table 12.

TABLE 9 Model results from negative binomial count model of number of bicycle crashes a person is involved in.

\begin{tabular}{|l|l|l|l|l|}
\hline Variable & IRR & Robust Std. Err. & z & P > $|z|$ \\
\hline Bike Attitude Strong & 3.367 & 1.644 & 2.49 & 0.013 \\
\hline Bike Attitude Enthused & 3.202 & 1.566 & 2.38 & 0.017 \\
\hline Bike Attitude Interested & 1 & Omitted & & \\
\hline Bike Attitude No Way & 1 & Omitted & & \\
\hline Day Lights Always & 2.388 & 0.936 & 2.22 & 0.026 \\
\hline Day Lights Usually & 1.220 & 0.408 & 0.60 & 0.551 \\
\hline Day Lights Sometimes & 1.347 & 0.468 & 0.86 & 0.391 \\
\hline Day Lights Rarely & 1.074 & 0.388 & 0.20 & 0.843 \\
\hline Day Lights Never & 1 & Omitted & & \\
\hline
\end{tabular}




\begin{tabular}{|l|l|l|l|l|}
\hline Night Lights Always & 0.872 & 0.427 & -0.28 & 0.780 \\
\hline Night Lights Usually & 0.816 & 0.432 & -0.38 & 0.701 \\
\hline Night Lights Sometimes & 0.544 & 0.726 & -0.46 & 0.648 \\
\hline Night Lights Rarely & 4.622 & 2.974 & 2.38 & 0.017 \\
\hline Night Lights Never & 1 & Omitted & & \\
\hline Stop Traffic Signals Always & 0.577 & 0.225 & -1.41 & 0.159 \\
\hline Stop Traffic Signals Usually & 0.431 & 0.188 & -1.93 & 0.053 \\
\hline Stop Traffic Signals Sometimes & 1 & Omitted & & \\
\hline Stop Traffic Signals Rarely & 1 & Omitted & & \\
\hline Stop Traffic Signals Never & 1 & Omitted & & \\
\hline Knowledge Helmet Laws & 2.487 & 0.802 & 2.82 & 0.005 \\
\hline Constant & 0.197 & 0.111 & -2.88 & 0.004 \\
\hline /lnalpha & -4.231 & 10.291 & & \\
\hline alpha & 0.015 & 0.150 & & \\
\hline
\end{tabular}

The above model tells us that compared to bikers who describe themselves as "interested but concerned" those that describe themselves as "strong and fearless" or "enthused and confident" are likely to be involved in more than 3 times as many crashes. We would surmise that this speaks to the relative safety of bicycling infrastructure in Virginia, those that are confident bikers state that they will bike "anywhere no matter the infrastructure" and "with dedicated infrastructure". These are bikers that are using the existing bike infrastructure or biking in areas where infrastructure has yet to be created. They are not tentatively avoiding places where they may encounter cars, and we believe this is why the likelihood of number of crashes increases for these riders. Additionally, bikers who always use lights on their bikes during the day compared to those who never do predicted to be involved in twice as many crashes. It would be illogical to conclude that having lights increases the likelihood of crashes. A possible explanation is that people who tend to bike in areas where they feel they need to be visible, like in areas where they will encounter cars will use lights during the day because of their more dangerous circumstances which are what lead to the increased likelihood of crashes. People who rarely use lights at night compared to those who never do are likely to get into more crashes. Bikers who always or usually stop at traffic signals are predicted to get into about half as many crashes as people who sometimes stop at traffic signals. This is a finding that supports Virginia's traffic control laws concerning bicyclists, where bicyclists are required to act as motor vehicles when approaching a traffic light. Finally, people who state knowing the Virginia helmet laws get into about 2.5 more crashes than those that do not. Again, it is not logical to conclude that knowing when to wear a helmet is a cause of crashes. It is likely that the helmet law knowledge variable like the daytime lights variable capturing some other differences among the respondents, perhaps knowledge and preparedness is representing experience or some other type of exposure.

\subsubsection{Multinomial Logit}

\subsubsection{How often do you wear a helmet while biking?}

A multinomial logit model was used to determine characteristics that influence a biker's decision to always, usually, sometimes, rarely, or never wear a helmet. Table 13 shows the results of the model parameters. Several characteristics of the respondent where found to influence the likelihood of each level of helmet usage. As age increases respondents are more likely to choose to wear a helmet always, sometimes, usually, or rarely compared to never wearing a helmet. This signifies that as people age they are more likely to wear a helmet more often than their younger counterparts. Older people are associated with a greater risk of injury in the event of a crash $(7,10,5,8)$ and this result signifies that some people may be more aware of this or are trying to counteract their limitations with safety elements like helmets. In the table below, "B" signifies the parameter coefficient estimates, "Std. Error" refers to the standard error of the estimate, "Sig. is the significance of the variable, and "Exp(B)" refers to the odds ratio of the variable. 
TABLE 10 Parameter estimates for helmet use multinomial logit model

\begin{tabular}{|c|c|c|c|c|c|}
\hline \multicolumn{2}{|l|}{ Helmet } & \multirow{2}{*}{\begin{tabular}{|l|} 
B \\
-3.399 \\
\end{tabular}} & \multirow{2}{*}{$\begin{array}{l}\begin{array}{l}\text { Std. } \\
\text { Error }\end{array} \\
.948 \\
\end{array}$} & \multirow{2}{*}{$\begin{array}{l}\text { Sig. } \\
.000 \\
\end{array}$} & \multirow[t]{2}{*}{$\operatorname{Exp}(B)$} \\
\hline \multirow[t]{10}{*}{ Always } & Intercept & & & & \\
\hline & Age & .174 & .034 & .000 & 1.190 \\
\hline & Do not know BUI law & 2.207 & .537 & .000 & 9.087 \\
\hline & Know BUI law & $0^{\mathrm{b}}$ & . & & \\
\hline & $\begin{array}{l}\text { Do not know traffic } \\
\text { stopping laws }\end{array}$ & -2.803 & .669 & .000 & .061 \\
\hline & $\begin{array}{l}\text { Know traffic stopping } \\
\text { laws }\end{array}$ & $0^{\mathrm{b}}$ & . & & . \\
\hline & Do not know helmet laws & -.412 & .464 & .374 & .662 \\
\hline & Know helmet laws & $0^{\mathrm{b}}$ & . & & \\
\hline & Male & .189 & .415 & .650 & 1.208 \\
\hline & Female & $0^{\mathrm{b}}$ &. & & \\
\hline \multirow[t]{10}{*}{ Rarely } & Intercept & -8.892 & 1.837 & .000 & \\
\hline & Age & .094 & .043 & .029 & 1.098 \\
\hline & Do not know BUI law & 2.664 & .734 & .000 & 14.358 \\
\hline & Know BUI law & $0^{\mathrm{b}}$ & & & \\
\hline & $\begin{array}{l}\text { Do not know traffic } \\
\text { stopping laws }\end{array}$ & -.895 & .697 & .199 & .409 \\
\hline & $\begin{array}{l}\text { Know traffic stopping } \\
\text { laws }\end{array}$ & $0^{\mathrm{b}}$ & . & & . \\
\hline & Do not know helmet laws & 2.278 & .757 & .003 & 9.755 \\
\hline & Know helmet laws & $0^{\mathrm{b}}$ & . & & \\
\hline & Male & 3.769 & 1.291 & .004 & 43.322 \\
\hline & Female & $0^{\mathrm{b}}$ & & & \\
\hline \multirow[t]{10}{*}{ Sometimes } & Intercept & -6.155 & 1.622 & .000 & \\
\hline & Age & .145 & .045 & .001 & 1.156 \\
\hline & Do not know BUI law & .393 & .944 & .677 & 1.481 \\
\hline & Know BUI law & $0^{\mathrm{b}}$ & . & & \\
\hline & $\begin{array}{l}\text { Do not know traffic } \\
\text { stopping laws }\end{array}$ & -21.409 & .000 & & $5.035 \mathrm{E}-10$ \\
\hline & $\begin{array}{l}\text { Know traffic stopping } \\
\text { laws }\end{array}$ & $0^{\mathrm{b}}$ & · & . & . \\
\hline & Do not know helmet laws & 2.629 & .930 & .005 & 13.857 \\
\hline & Know helmet laws & $0^{\mathrm{b}}$ &. & & . \\
\hline & Male & -.701 & .875 & .423 & .496 \\
\hline & Female & $0^{\mathrm{b}}$ & . & & \\
\hline \multirow[t]{6}{*}{ Usually } & Intercept & -3.981 & 1.034 & .000 & \\
\hline & Age & .137 & .035 & .000 & 1.146 \\
\hline & Do not know BUI laws & 1.572 & .572 & .006 & 4.817 \\
\hline & Know BUI law & $0^{\mathrm{b}}$ & . & & \\
\hline & $\begin{array}{l}\text { Do not know traffic } \\
\text { stopping laws }\end{array}$ & -3.896 & 1.244 & .002 & .020 \\
\hline & $\begin{array}{l}\text { Know traffic stopping } \\
\text { laws }\end{array}$ & $0^{\mathrm{b}}$ & . & & \\
\hline
\end{tabular}




\begin{tabular}{|l|l|l|l|l|l|}
\hline \multirow{7}{*}{} & Do not know helmet laws & -.315 & .505 & .533 & .730 \\
\cline { 2 - 6 } & Know helmet laws & $0^{\mathrm{b}}$ &. &. &. \\
\cline { 2 - 6 } & Male & .993 & .529 & .061 & 2.698 \\
\cline { 2 - 6 } & Female & $0^{\mathrm{b}}$ &. &. &. \\
\hline
\end{tabular}

a. The reference category is: Never.

b. B. This parameter is set to zero because it is redundant.

\subsubsection{Which describes your attitude towards bicycling?}

A multinomial logit model was run to determine which characteristics impact the attitude of a bicyclist, or their confidence level while biking. The results of this model are displayed in table 14. Several characteristics proved to be statistically significant including recent bike history, understanding of how bicyclists should behave at stop signs and traffic lights, gender, use of lights during the day and use of reflective clothing at night. People who had not biked in the past week were less likely to state feeling enthused and confident or strong and fearless compared to interested but concerned. People who stated they did not know how bicyclists are required to behave at stop signs and traffic lights were also much less likely to report having an enthused/confident or strong/fearless attitude compared to an interested/concerned attitude. This indicates that when bikers understand the rules of the road they feel more comfortable and confident biking. Additionally, males are almost three times as likely as females to say they are enthused/confident rather than interested/concerned and males are also almost seven times as likely as females to say they are strong/fearless rather than interested/concerned. Additionally, people who never or sometimes use reflective clothing and lights on their bikes are much more likely to describe their attitude towards biking as confident or fearless rather than interested/concerned.

Table 11 Parameter Estimates for multinomial logit model of bicycling attitude.

\begin{tabular}{|c|c|c|c|c|c|}
\hline \multicolumn{2}{|l|}{ Bike Attitude $^{\mathrm{a}}$} & $\mathrm{B}$ & Std. Error & Sig. & $\operatorname{Exp}(B)$ \\
\hline \multirow{17}{*}{$\begin{array}{l}\text { Enthused and } \\
\text { confident - I like to } \\
\text { ride and am confident } \\
\text { doing so with } \\
\text { dedicated } \\
\text { infrastructure }\end{array}$} & Intercept & 3.463 & .963 & .000 & \\
\hline & Biked last week - no & -4.436 & .717 & .000 & .012 \\
\hline & Biked last week - yes & $0^{\mathrm{b}}$ &. &. & \\
\hline & $\begin{array}{l}\text { Do not know traffic stopping } \\
\text { laws }\end{array}$ & -1.854 & .849 & .029 & .157 \\
\hline & Know traffic stopping laws & $0^{\mathrm{b}}$ & . & . & 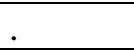 \\
\hline & Male & 1.069 & .596 & .073 & 2.913 \\
\hline & Female & $0^{\mathrm{b}}$ & $\cdot$ & $\cdot$ & \\
\hline & Bike Lights Day - Never & -2.608 & 1.077 & .015 & .074 \\
\hline & Bike Lights Day - Rarely & -2.181 & .940 & .020 & .113 \\
\hline & Bike Lights Day - Sometimes & .255 & 1.311 & .846 & 1.290 \\
\hline & Bike Lights Day - Usually & -.735 & 1.017 & .470 & .480 \\
\hline & Bike Lights Day - Always & $0^{\mathrm{b}}$ & &. & \\
\hline & $\begin{array}{l}\text { Reflective Clothing Night - } \\
\text { Never }\end{array}$ & 5.134 & 1.923 & .008 & 169.718 \\
\hline & $\begin{array}{l}\text { Reflective Clothing Night - } \\
\text { Rarely }\end{array}$ & 1.437 & 1.544 & .352 & 4.209 \\
\hline & $\begin{array}{l}\text { Reflective Clothing Night - } \\
\text { Sometimes }\end{array}$ & 3.809 & 1.150 & .001 & 45.089 \\
\hline & $\begin{array}{l}\text { Reflective Clothing Night - } \\
\text { Usually }\end{array}$ & -.398 & .730 & .585 & .671 \\
\hline & $\begin{array}{l}\text { Reflective Clothing Night - } \\
\text { Always }\end{array}$ & $0^{\mathrm{b}}$ & - & . & . \\
\hline
\end{tabular}




\begin{tabular}{|c|c|c|c|c|c|}
\hline \multirow{17}{*}{$\begin{array}{l}\text { Strong and fearless - } \\
\text { I will ride anywhere, } \\
\text { no matter the } \\
\text { facilities provided }\end{array}$} & Intercept & 2.052 & 1.007 & .042 & \\
\hline & Biked last week - no & -5.921 & .776 & .000 & .003 \\
\hline & Biked last week - yes & $0^{\mathrm{b}}$ & & &. \\
\hline & $\begin{array}{l}\text { Do not know traffic stopping } \\
\text { laws }\end{array}$ & -2.883 & .988 & .004 & .056 \\
\hline & Know traffic stopping laws & $0^{\mathrm{b}}$ & & & . \\
\hline & Male & 1.913 & .626 & .002 & 6.776 \\
\hline & Female & $0^{\mathrm{b}}$ & & & . \\
\hline & Bike Lights Day - Never & -1.788 & 1.103 & .105 & .167 \\
\hline & Bike Lights Day - Rarely & -1.722 & .973 & .077 & .179 \\
\hline & Bike Lights Day - Sometimes & .904 & 1.341 & .500 & 2.469 \\
\hline & Bike Lights Day - Usually & .741 & 1.045 & .479 & 2.098 \\
\hline & Bike Lights Day - Always & $0^{\mathrm{b}}$ & & & \\
\hline & $\begin{array}{l}\text { Reflective Clothing Night - } \\
\text { Never }\end{array}$ & 5.614 & 1.936 & .004 & 274.144 \\
\hline & $\begin{array}{l}\text { Reflective Clothing Night - } \\
\text { Rarely }\end{array}$ & 2.185 & 1.554 & .160 & 8.888 \\
\hline & $\begin{array}{l}\text { Reflective Clothing Night - } \\
\text { Sometimes }\end{array}$ & 4.240 & 1.174 & .000 & 69.406 \\
\hline & $\begin{array}{l}\text { Reflective Clothing Night - } \\
\text { Usually }\end{array}$ & .568 & .741 & .444 & 1.764 \\
\hline & $\begin{array}{l}\text { Reflective Clothing Night - } \\
\text { Always }\end{array}$ & $0^{\mathrm{b}}$ & . & . & . \\
\hline
\end{tabular}

a. The reference category is: Interested but concerned - I like the idea of riding, but I have concerns.

b. This parameter is set to zero because it is redundant.

\subsection{CONCLUSIONS AND LIMITATIONS}

\subsubsection{Conclusions}

The results of this survey project provide insight into the attitudes and feelings of active bicyclists in Virginia. One of the most impactful conclusions from this research was in the crash information reported by respondents. We found in this research that only $12 \%$ of the crashes detailed in our survey were reported to the police. This is smaller than expected based on literature on underreporting of bicycle crashes. Additionally, from the multinomial logit modeling of respondent attitudes toward bicycling we showed that not understanding the laws of the road is associated with less confidence towards biking. This suggests to us that education on bicycle laws would not only help people be safer on the road, but could get more people on the road in the first place. Additionally, males were reported as being much more likely to describe their attitude towards biking as enthused, confident or fearless rather than interested or concerned when compared to women. This makes us question whether the gender gap in bicycling is because women are more concerned outright and therefore don't pursue biking as often as men. In this case, the reasons for their concern should be investigated Additionally, from the MNL modeling of helmet use we saw that as people get older they are less likely to say that they never wear a helmet. This is encouraging because as people age they become more prone to injury. Finally, the negative binomial count model examining variables that impact the number of crashes a person is involved indicates that bikers who always or usually stop at traffic signals are predicted to get into about half as many crashes as people who sometimes stop at traffic signals. This supports Virginia legislature that requires bicyclists to act like motor vehicles at traffic lights and fully stop. States like Idaho allow bicyclists to treat traffic lights more like a stop sign, this is not the case in Virginia and the results of this model appear to support the current legislature. 


\subsubsection{Limitations}

One limitation of this analysis is in the survey population, that we suspect it is made up of many highly active bicyclists and less casual riders. This makes the survey responses biased towards people who are more comfortable riding and more experienced riders. This is a result of both our approach to distributing the survey as well as the inherent nature of all survey responders, that people may answer because it is a subject that they are interested in. Our survey distribution approach largely involved contacting bicycle clubs, organizations, and advocacy groups around Virginia. While this enabled us to achieve our target number of responses, a strategy for locating and contacting more casual riders may have given us a more balanced survey population. We did however complete a weighting process and we would expect that our population is more reflective of the entire Virginia biking population.

Additionally, in our survey an open-ended question at the end of the survey that prompted respondents to give additional comments, expand upon questions or give suggestions about the survey was utilized by many respondents. Through this question we were able to gain insight into the many different thoughts bicyclists have about roads, infrastructure, cars, safety, laws, and education. One comment that alerted us to a possible area in which our survey could have been expanded were those that discussed a wish for questions about kids and how their travel and safety needs are different from adults. While we feel that the length of our survey at present was already long enough to provoke survey fatigue from respondents, children's bicycling experience is an important topic. We are reminded that bike infrastructure should continuously strive to be accessible, safe, and comfortable for all users including our society's most vulnerable riders, children, and not just for confident or experienced riders.

\section{CONCLUSION}

The overarching goal for this research has been to better understand bicyclist safety in Virginia by determining factors that both positively and negatively impact the safety of these road users. Through the Virginia police crash report analysis factors relating to bicyclists, automobile drivers, vehicles, the environment, and roadway characteristics were examined to determine which characteristics impact the likelihood of more severe injuries. The analysis informed us that despite significant gains in safety through driving under the influence legislation, drunk drivers still pose a serious risk not just to other drivers but to more vulnerable road users. A drunk driver in a bike crash was found to increase the probability of cyclist fatality by six. Additionally, biking under the influence increases the risk of the bicyclists own death or injury. This result spurred an ultimately inconclusive advance into the United States legislation on bicycling under the influence laws. In the future, with alternative and more comprehensive data, we still hope to answer the question on effectiveness of BUI laws. Additionally, problems with expectation and visibility of bicyclists were found to impact injury severity in bicyclist crashes. This was determined through the impact of variables such as obscured automobile driver vision, vehicle types, vertical roadway grades, and horizontal curves. Furthermore, bicycle and automobile speeds elevated the likelihood of more severe bicyclist injuries, encouraging the incorporation of bicycle infrastructure on low speed roads.

After working with a dataset that only captured police reported automobile-bicycle crashes, we were encouraged to seek out more data that better represents all bicycle crashes. From the literature, it was clear that many bicycle crashes are highly underreported to the police and therefore not captured in our sample. The survey was designed to capture more information about all bicycle crashes as well as a more human component of safety that is not captured in police reports. We felt that bicyclist perception of safety on the road, and their relationship with other drivers and the infrastructure would be important information to pursue when trying to obtain a complete picture of bicyclist safety. One of the most meaningful findings in the survey data analysis concerned the crash data that was collected from survey respondents. Of the 412 crashes recorded, only $12 \%$ were reported to the police. This highlights the depth of underreporting in bicycle crashes and clarifies the limitations of police crash report based datasets. Additionally, we were 
able to glean from our survey questions that bicyclist understanding of how to behave on the road is associated with bicycling confidence and safety. Removing educational barriers to getting bikers on the road can in turn improve safety for everyone by increasing the number of bikers.

The results from this work provide us with a thorough picture of bicycle safety in Virginia and adds to existing literature on factors that can influence the safety of bicyclists. Future work from this project will involve further analysis of the survey for additional information. The data produced through the survey has not yet been exhausted of usefulness. Some examples include additional work analyzing the detailed crash information provided by respondents who had been in crashes. Bicyclists were asked to include crash information based on variables we found were particularly important for bicyclists following the police crash report dataset analysis. Additionally, this work has focused largely on the actions and feelings of bicyclists, but we also have some information about people who choose not to bike and why which has not been thoroughly examined. This could serve as another analysis route. Finally, alternative datasets could be gathered to help in answering questions about the effectiveness of bicycling under the influence laws. Each of these questions will help to further our knowledge on methods to improve bicycle safety to ultimately make this mode safer and more enjoyable for all users. 


\section{ACKNOWLEDGEMENTS}

Appreciation is extended to Lam Phan, the data manager at the Virginia Department of Motor Vehicles, for providing the police crash report data for part one of this work.

The second part of this research, the development of the survey, benefited from the input of people who work in the bicycle research, safety and planning fields. Peter Ohlms from the Virginia Transportation Research Council and Amanda Poncy, the Charlottesville bicycle and pedestrian coordinator, provided input on the survey questions and connected me with the Charlottesville Bicycle and Pedestrian Committee. John Bolecek, the statewide pedestrian and bicycle planner also reviewed a draft of the survey as did Amy O'Leary, who has expertise in survey design and gave meaningful feedback on the survey questions.

I am also very appreciative of everyone who piloted the early, middle, and final drafts of the bicycle attitude and safety survey, particularly my colleagues within my research group.

Special thanks to all of my friends and family who have supported me during the two-year journey to my master's degree. You all make my life so exciting and fun.

And lastly thank you to my amazing advisor, Donna Chen, I am grateful that we both began new chapters in our lives at the University of Virginia two years ago and I look forward to continuing to work together towards my Ph.D. 


\section{REFERENCES}

An Act to Amend Title 221 of the Delaware Code Relating to Bicycling, Senate Bill U.S.C. (1995). http://www.delcode.delaware.gov/sessionlaws/ga138/chp265.shtml

An Act Relating to Rights and Duties of Bicyclists, House Bill U.S.C. (2000).

http://lawfilesext.leg.wa.gov/biennium/1999-

00/Pdf/Bills/Session\%20Laws/House/2333.SL.pdf?cite=2000\%20c\%2085\%20\%C2\%A7\%204

Andersen, L., Schnohr, P., Schroll, M., \& Hein, H. (2000). All-cause mortality associated with physical activity during leisure time, work, sports, and cycling to work. Arch Intern Med, 160(11), 16211628.

Andersson, A., \& Bunketorp, O. (2002). Cycling and alcohol. Injury, 33(6), 467-471.

B. McKenzie, "Modes Less Traveled-Bicycling and Walking to Work in the United States: 2008-2012," United States Census Bureau, 2014.

Bassett, D. J., Pucher, J., Buehler, R., Thompson, D., \& Crouter, S. (2008). Walking, cycling, and obesity rates in europe, north america, and australia. Journal of Physical Activity and Health, 5(6), 795 814.

"Census Geocoder," 25 January 2017. [Online]. Available: https://www.census.gov/geo/mapsdata/data/geocoder.html.

Chen, T. D., \& Kockelman, K. M. (2012). Roles of vehicle footprint, height, and weight in crash outcomes: Application of a heteroscedastic ordered probit model. Transportation Research Record: Journal of the Transportation Research Board, 2280, 89-99.

D. Shinar, M. Houtenbos, N. Haworth, A. Schramm, P. Valero-Mora, O. Mascarell, A. Fyhri, A. Hursa, G. De Bruyne and A. Morandi, "Reporting bicycle accidents to police in the COST TU1101 survey data base: Cross-country comparisons and associated factors," in 5th International Cycling Safety Conference, Bologna, Italy, 2016

De Hartog, J. J., Boogaard, H., Nijland, H., \& Hoek, G. (2010). Do the health benefits of cycling outweigh the risks? Environmental Health Perspective, 118(8), 1109-1116.

Eluru, N., Bhat, C. R., \& Hensher, D. A. (2008). A mixed generalized ordered response model for examining pedestrian and bicyclist injury severity level in traffic crashes. Accident Analysis and Prevention, 40(3), 1033-1054.

F. Harrell, "Binary Logistic Regression," in Regression Modeling Strategies, Springer, Cham, Springer Series in Statistics, 2015.

Farmer, C. M. (2003). Reliability of police-reported information for determining crash and injury severity. Traffic Injury Prevention, 4(1), 38-44. doi:10.1080/15389580309855

Fatality analysis reporting system. (2014). 2016, from http://www-fars.nhtsa.dot.gov/Main/index.aspx

Galbraith, M. Sharing Kentucky's roads: KY laws for drivers and bicyclists. Kentucky Transportation Cabinet.

Garrick, N. W., \& Marshall, W. E. (2011). Evidence on why bike-friendly cities are safer for all road users. Environmental Practice, 13(1), 16-27.

Greene, W. H. (2008). Econometric analysis. Upper Saddle River, New Jersey: Pearson Prentice Hall.

Hingson, R., Heeren, T., Winter, M. (1996). Lowering state legal blood alcohol limits to $0.08 \%$ : the effect on fatal motor vehicle crashes. American Journal of Public Health, 109, 738-744

J. Dill, N. W. McNeil and C. M. Monsere, "A Comparison of Survey Methods for Bicycle Research," in TRB 2016 Annual Meeting, Washington, D.C., 2016. 
Khattak, A. J., Kantor, P., \& Council, F. (1998). Role of adverse weather in key crash types on limitedaccess: Roadways implications for advanced weather systems. Transportation Research Record: Journal of the Transportation Research Board, 1621, 10-19.

Kim, J., Kim, S., Ulfarsson, G. F., \& Porrell, L. A. (2007). Bicyclist injury severities in bicycle-motor vehicle accidents. Accident Analysis and Prevention, 39(2), 238-251.

Klop, J. R., \& Khattak, A. J. (1999). Factors influencing bicycle crash severity on two-lane, undivided roadways in North Carolina. Transportation Research Record: Journal of the Transportation Research Board, 1674, 78-85.

Laerd Statistics. (2013). Binomial Logistic Regression using SPSS statistics. Retrieved July, 2017, from https://statistics.laerd.com/spss-tutorials/binomial-logistic-regression-using-spssstatistics.php

Laerd Statistics. (2013). Multinomial logistic regression using SPSS statistics. Retrieved July, 2017, from https://statistics.laerd.com/spss-tutorials/multinomial-logistic-regression-using-spssstatistics.php

Laerd Statistics. (2013). Poisson regression analysis using SPSS statistics. Retrieved July, 2017, from https://statistics.laerd.com/spss-tutorials/poisson-regression-using-spss-statistics.php

Longhitano, D., Henary, B., Bhalla, K., Ivarsson, J. et al., "Influence of Vehicle Body Type on Pedestrian Injury Distribution," SAE Technical Paper 2005-01-1876, 2005, doi:10.4271/2005-01-1876.

Madsen, J.C.O., Andersen, T, Lahrmann, H.S. (2013). Safety effects of permanent running lights for bicycles: A controlled experiment. Accident Analysis and Prevention, 50, 820-829.

McLeod, K. (2013). Bike law university: Idaho stop. Retrieved July, 2017, from http://bikeleague.org/content/bike-law-university-idaho-stop

McLeod, K. (2013). Bike law university: Riding under the influence. Retrieved July/2016, 2016, from http://bikeleague.org/content/bike-law-university-riding-under-influence

Moore, D. N., Schneider IV, W. H., Savolainen, P. T., \& Farzaneh, M. (2011). Mixed logit analysis of bicyclist injury severity resulting from motor vehicle crashes at intersection and non-intersection locations. Accident Analysis and Prevention, 43(3), 621-630.

National Center for Statistics and Analysis. (2016, May). Bicyclists and other cyclists: 2014 data (Traffic Safety Facts No. DOT HS 812 282). Washington, DC: National Highway Traffic Safety Administration.

P. Jacobsen, "Safety in numbers: more walkers and bicyclists, safer walking and bicycling," Injury Prevention, vol. 9, pp. 205-209, 2003.

Passing bicycle, electric personal assistive mobility device, electric power-assisted bicycle, moped, animal, or animal-drawn vehicle, 46.2 Code of Virginia $\$ 46.2-839$ (2014).

R. Elvik and T. Bjornskau, "Safety-in-numbers: A systematic review and meta-analysis of evidence," Safety Science, pp. 274-282, 2017.

Rasanen, M., \& Summala, H. (1997). Attention and expectation problems in bicycle-car collisions: An in-depth study. Accident Analysis and Prevention, 30(5), 657-666.

"Regression Analysis in NCSS," 2017. [Online]. Available: https://ncss-wpengine.netdna-ssl.com/wpcontent/themes/ncss/pdf/Procedures/NCSS/Poisson_Regression.pdf.

Reynolds, C. C., Harris, M. A., Teschke, K., Cripton, P. A., \& Winters, M. (2009). The impact of transportation infrastructure on bicycling injuries and crashes: A review of the literature. Environmental Health, 8:47

Rodgers, G. B. (1995). Bicyclist death and fatality risk patterns. Accident Analysis and Prevention, 27(2), 215-223.

S. Yao and B. P. Loo, "Safety in numbers for cyclists beyond national-level and city-level data: a study on the non-linearity of risk within the city of Hong Kong," Injury Prevention, vol. 22, pp. 379385, 23 June 2016. 
Sethi, M., Heyer, J. H., Wall, S., DiMaggio, C., Shinseki, M., Slaughter, D., et al. (2016). Alcohol use by urban bicyclists is associated with more severe injury, greater hospital resource use, and higher mortality. Alcohol, 53, 1-7.

Shouse California Law Group. (2017). Cycling / biking under the influence (CUI) california vehicle code 21200.5 VC. Retrieved July, 2017, from http://www.shouselaw.com/cycling-biking-underinfluence.html

Stutts, J. C., \& Hunter, W. W. (1998). Police reporting of pedestrians and bicyclists treated in hospital emergency rooms. Transportation Research Record: Journal of the Transportation Research Board, 1635, 88-92.

Traffic lights; penalty, 46.2 Code of Virginia $§ 46.2-833$ (2013).

U.S. Census Bureau (2015). Commuting Characteristics American Community Survey 1-Year Estimates. Retrieved April 2017 from https://factfinder.census.gov/faces/tableservices/jsf/pages/productview.xhtml?pid=ACS_15_1YR S0801\&prodType=table

Virginia Department of Motor Vehicles. (July 2015). FR 300M crash report manual: Virginia state crash report training manual. Retrieved July 2016, from https://www.dmv.virginia.gov/safety/pdf/crash_report_instruction.pdf

Virginia Department of Transportation. (February 2016). Bicycling and walking in Virginia: Laws and safety tips. Retrieved July 2016, 2016, from http://www.virginiadot.org/programs/bk-laws.asp

Voas, R., Tippetts, A., Fell, J. (2003). Assessing the effectiveness of minimum legal drinking age and zero tolerance laws in the United States. Accident Analysis and Prevention, 35, 579-587.

Wang, X., \& Kockelman, K. M. (2005). Use of heteroscedastic ordered logit model to study severity of occupant injury: Distinguishing effects of vehicle weight and type. Transportation Research Record: Journal of the Transportation Research Board, 1908, 195-204.

Yan, X., Huang, H., Abdel-Aty, M., \& Wu, C. (2011). Motor vehicle-bicycle crashes in Beijing: Irregular maneuvers, crash patterns, and injury severity. Accident Analysis and Prevention, 43(5), 17511758.

Ye, F., \& Lord, D. (2014). Comparing three commonly used crash severity models on sample size requirements: Multinomial logit, ordered probit and mixed logit models. Analytic Methods in Accident Research, 1, 72-85. 


\section{APPENDIX}

7.1 Virginia Bicycling Safety Survey 


\section{Virginia Bicycling Safety Survey}

This survey asks about your travel choices, focusing on bicycle travel. The results of this survey will be used for research purposes to better understand perceptions of bicycling

safety in Virginia. Your feedback is anonymous and we are very interested in your responses even if you never bike. This survey should take approximately 15 minutes, we appreciate your participation!

\section{Questions about your recent travel:}

The following questions ask about your participation in various activities in the past week.

Please note that one trip is defined as traveling from a starting point to a destination. If you leave your home to go on a walk, make no stops and return home that would be defined as one trip. If you drive to the grocery store, go shopping, and then return home, that would be two trips.

1. In the past week have you used a bike? Yes $\square \quad$ No $\square$ (skip question 2)

2. Please record how many trips you took on a bike in the past week.

\begin{tabular}{|l|l|l|l|l|l|l|l|}
\hline & Sunday & Monday & Tuesday & Wednesday & Thursday & Friday & Saturday \\
\hline $\begin{array}{l}\text { Biked to a destination (such } \\
\text { as work, school, the grocery } \\
\text { store, a public transit stop, a } \\
\text { restaurant, etc.) }\end{array}$ & & & & & & \\
\hline $\begin{array}{l}\text { Biked for recreation or } \\
\text { exercise }\end{array}$ & & & & & & & \\
\hline
\end{tabular}

3. In the past week have you walked to a destination or walked for recreation or exercise?

$$
\text { Yes } \square \quad \text { No } \square(\text { skip question 4) }
$$

4. Please record how many trips you took by walking in the past week.

\begin{tabular}{|l|l|l|l|l|l|l|l|}
\hline & Sunday & Monday & Tuesday & Wednesday & Thursday & Friday & Saturday \\
\hline $\begin{array}{l}\text { Walked to a destination } \\
\text { (such as work, school, the } \\
\text { grocery store, a public } \\
\text { transit stop, a restaurant, } \\
\text { etc.) }\end{array}$ & & & & & & \\
\hline $\begin{array}{l}\text { Walked for recreation or } \\
\text { exercise (walking with no } \\
\text { particular destination) }\end{array}$ & & & & & & & \\
\hline
\end{tabular}

5. In the past week did you use public transit?

Yes $\mathrm{C}$

No $\square$ (skip question 6) 
6. Please record how many trips you made by public transit in the past week.

\begin{tabular}{|l|l|l|l|l|l|l|l|}
\hline & Sunday & Monday & Tuesday & Wednesday & Thursday & Friday & Saturday \\
\hline $\begin{array}{l}\text { Used public } \\
\text { transit }\end{array}$ & & & & & & & \\
\hline
\end{tabular}

7. In the past week were you a passenger or a driver in an automobile?

$$
\text { Yes } \square \quad \text { No } \square \text { (skip question 8) }
$$

8. Please record how many trips you took by automobile in the past week?

\begin{tabular}{|l|l|l|l|l|l|l|l|}
\hline & Sunday & Monday & Tuesday & Wednesday & Thursday & Friday & Saturday \\
\hline $\begin{array}{l}\text { Were a passenger or a } \\
\text { driver in an } \\
\text { automobile. }\end{array}$ & & & & & & & \\
\hline
\end{tabular}

9. Do you feel that this week was representative of a typical week of travel for you?

$$
\text { Yes } \square \quad \text { No }
$$

10. Compared to last year around this time do you feel that you are now bicycling more, about the same, or less? $\quad$ More $\square \quad$ About the same $\square \quad$ Less $\square$

11. Do you participate in a bikeshare program? $\quad$ Yes $\square \quad$ No $\square$

12. Do you use an electric bike? $\quad$ Yes $\square \quad$ No $\square$

13. Which describes your attitude toward bicycling?

$\square$ Strong and fearless - I will ride anywhere, no matter the facilities provided

$\square$ Enthused and confident - I like to ride and am confident doing so with dedicated infrastructure

$\square$ Interested, but concerned - I like the idea of riding, but I have concerns

$\square$ No way, no how

14. If you do not ride a bike, what is the reason? Please check all that apply.
$\square$ I do ride a bike.
$\square$ I don't own a bike
$\square$ Health/physical limitations
$\square$ Personal safety
$\square$ Lack of bike infrastructure
$\square$ No secure storage at my destination

Safety concerns about traffic (such as other vehicles, or intersection navigation)

Other

\section{Questions about bicycling safety:}

Describe how often you use the following bicycle safety equipment: 
I have not ridden a bike in the past year (skip questions 15 through 24)

\begin{tabular}{|c|l|l|l|l|l|}
\hline & Always & Usually & Sometimes & Rarely & Never \\
\hline $\begin{array}{c}\text { 15. How often do you wear a } \\
\text { helmet while biking? }\end{array}$ & & & & \\
\hline $\begin{array}{c}\text { 16. How often do you use lights on } \\
\text { your bike during the day? }\end{array}$ & & & & & \\
\hline
\end{tabular}

Describe how often you use the following bicycle safety equipment at night:

I do not ride my bike at night (skip questions 17 and 18)

\begin{tabular}{|c|l|l|l|l|l|}
\hline & Always & Usually & Sometimes & Rarely & Never \\
\hline $\begin{array}{l}\text { 17. How often do you wear } \\
\text { reflective clothing while } \\
\text { biking at night? }\end{array}$ & & & & & \\
\hline $\begin{array}{l}\text { 18. How often do you use lights on } \\
\text { your bike at night? }\end{array}$ & & & & & \\
\hline
\end{tabular}

For each question describe your bicycling experience.

\begin{tabular}{|c|c|c|c|c|c|}
\hline & Always & Usually & Sometimes & Rarely & Never \\
\hline $\begin{array}{l}\text { 19. When drivers pass you, they are } \\
\text { at least three feet to the left of } \\
\text { your bicycle. }\end{array}$ & & & & & \\
\hline 20. Drivers pass you too closely & & & & & \\
\hline $\begin{array}{l}\text { 21. Drivers are aggressive or } \\
\text { hostile towards you }\end{array}$ & & & & & \\
\hline $\begin{array}{l}\text { 22. When you approach a stop sign } \\
\text { on a bicycle, you stop. }\end{array}$ & & & & & \\
\hline $\begin{array}{l}\text { 23. When you approach a red light } \\
\text { at a traffic signal on a bicycle, } \\
\text { you stop. }\end{array}$ & & & & & \\
\hline $\begin{array}{l}\text { 24. You ride your bicycle on the } \\
\text { appropriate side of the road } \\
\text { with the flow of traffic. }\end{array}$ & & & & & \\
\hline
\end{tabular}

Describe the way you act towards bicyclists when you are driving a motor vehicle:

I have not driven a motor vehicle in the past year (skip questions 25 through 27) 


\begin{tabular}{|c|l|l|l|l|l|}
\hline & Always & Usually & Sometimes & Rarely & Never \\
\hline $\begin{array}{c}\text { 25. I pass bicyclists at least } \\
\text { three feet to the left of } \\
\text { the bicycle }\end{array}$ & & & & & \\
\hline $\begin{array}{l}\text { 26. I pass bicyclists within } \\
\text { three feet of the bicycle }\end{array}$ & & & & & \\
\hline $\begin{array}{l}\text { 27. Bicyclists act } \\
\text { aggressively when I } \\
\text { am driving }\end{array}$ & & & & & \\
\hline
\end{tabular}

28. Do you know who among Virginia cyclists are required to wear helmets?

Yes $\square \quad$ No $\square$

29. Are you aware of when Virginia bicyclists are required to use headlights and reflectors?

Yes $\square \quad$ No

Do you know how the driving under the influence law in Virginia applies to bicyclists?

Yes $\square \quad$ No $\square$

30. Are you aware of how bicyclists are required to behave at stop signs and traffic lights?

Yes $\square \quad$ No

31. How many bicycle crashes have you been involved in during the last 10 years? (Where you were either a motor vehicle driver, the bicyclist, or a pedestrian)

$\begin{array}{lll}\square \text { Zero } & \square \text { Three } & \\ \square \text { One } & \square \text { Four } & \square \text { More Than Five } \\ \square \text { Two } & \square \text { Five } & \end{array}$

If zero, skip question 32

32. Please check the appropriate boxes in the following table to provide information about the crash(es) you were involved in. Injury level can be defined by the following four categories:

Serious Injury (e.g. broken bones, lacerations, significant burns, crush injuries, paralysis)

Minor Injury (Other visible but less serious injuries, e.g. bruises, abrasions, swelling, limping)

No Apparent (Injury is not visible, but some pain felt, fainted)

No Injury

\begin{tabular}{|c|c|c|c|c|c|c|}
\hline & & Crash & Crash & Crash & Crash & Crash 5 \\
\hline \multirow{3}{*}{$\begin{array}{c}\text { Bicyclist } \\
\text { Injury } \\
\text { Level } \\
\text { (check one) }\end{array}$} & Severe Injury & 1 & 2 & 3 & 4 & \\
\hline & Minor Injury & & & & & \\
\hline & No Apparent Injury & & & & & \\
\hline $\begin{array}{c}\text { Other } \\
\text { vehicles in } \\
\text { the crash }\end{array}$ & No Injury & & & & & \\
\cline { 2 - 6 } & Passenger car (sedan, wagon) & & & & & \\
\hline & Pickup truck or SUV or van & & & & & \\
\hline
\end{tabular}




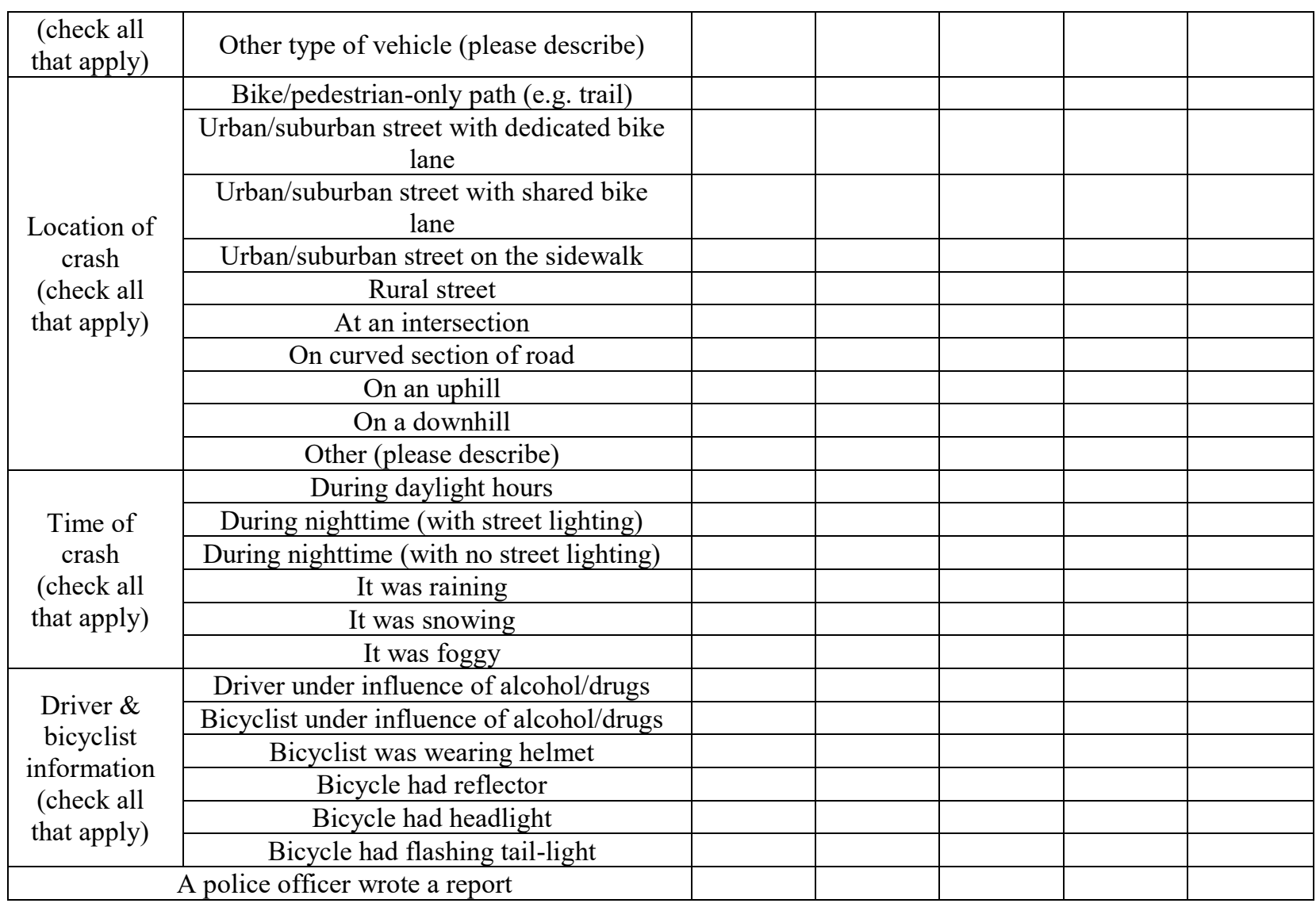

Please indicate how you feel about the following statements concerning safe biking experiences:

\begin{tabular}{|c|c|c|c|c|c|}
\hline & $\begin{array}{c}\text { Strongly } \\
\text { Agree }\end{array}$ & $\begin{array}{c}\text { Somewhat } \\
\text { Agree }\end{array}$ & $\begin{array}{c}\text { Neither } \\
\text { Agree nor } \\
\text { Disagree }\end{array}$ & $\begin{array}{c}\text { Somewhat } \\
\text { Disagree }\end{array}$ & $\begin{array}{c}\text { Strongly } \\
\text { Disagree }\end{array}$ \\
\hline $\begin{array}{c}\text { 33. I feel safe riding a bike in a } \\
\text { dedicated bike lane }\end{array}$ & & & & & \\
\hline $\begin{array}{l}\text { 34. I feel safe sharing the road } \\
\text { with cars when I bike. }\end{array}$ & & & & & \\
\hline
\end{tabular}




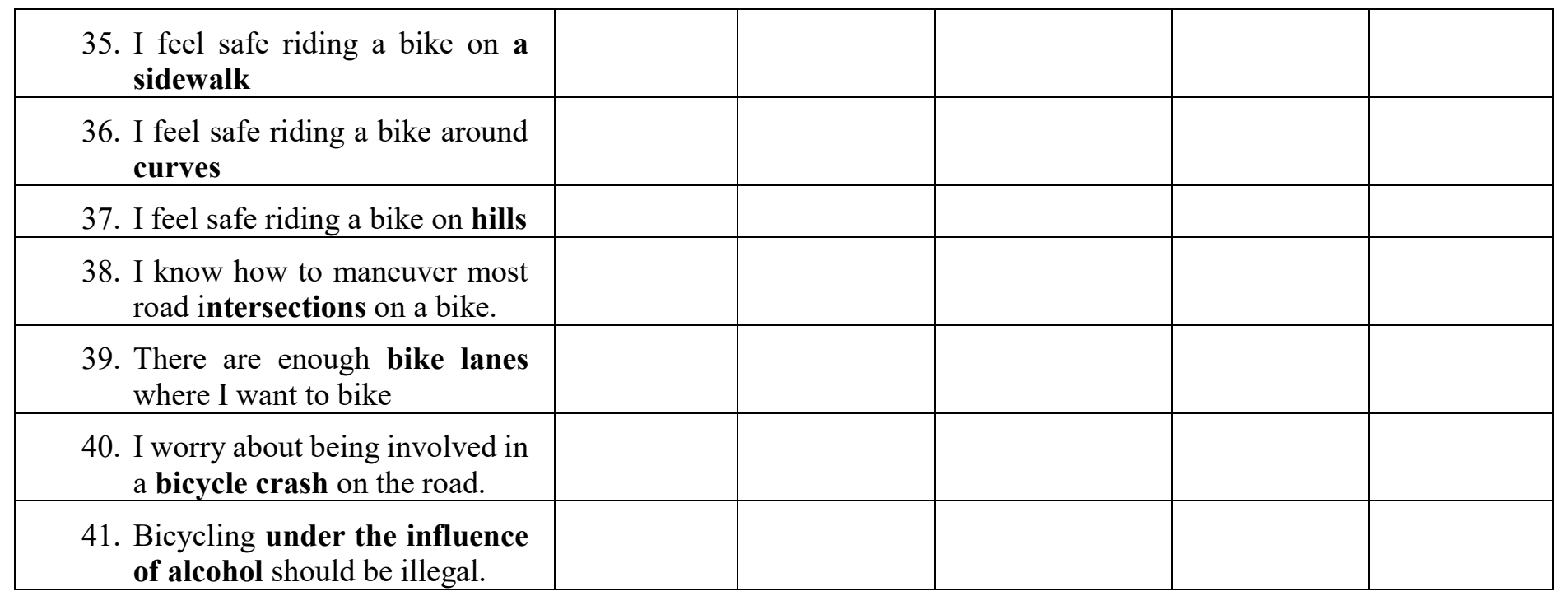

Please indicate how you feel about the following statements concerning bicycling and technology:

\begin{tabular}{|c|c|c|c|c|c|}
\hline & $\begin{array}{c}\text { Strongly } \\
\text { Agree }\end{array}$ & $\begin{array}{c}\text { Somewhat } \\
\text { Agree }\end{array}$ & $\begin{array}{l}\text { Neither } \\
\text { Agree nor } \\
\text { Disagree }\end{array}$ & $\begin{array}{l}\text { Somewhat } \\
\text { Disagree }\end{array}$ & $\begin{array}{l}\text { Strongly } \\
\text { Disagree }\end{array}$ \\
\hline $\begin{array}{l}\text { 42. Compared to human drivers, } \\
\text { automated vehicles (self-driving } \\
\text { cars) will be safer when sharing the } \\
\text { road with bicyclists. }\end{array}$ & & & & & \\
\hline $\begin{array}{l}\text { 43. If a device on your bike were } \\
\text { developed that would allow your } \\
\text { presence to be detected by } \\
\text { nearby vehicles (to increase their } \\
\text { awareness of your presence on the } \\
\text { road), you would use it. }\end{array}$ & & & & & \\
\hline $\begin{array}{l}\text { 44. You would be willing to pay a } \\
\text { one-time fee for such a device }\end{array}$ & & & & & \\
\hline
\end{tabular}

45. How much would you be willing to pay for a device on your bike that would allow your presence to be detected by nearby vehicles?

\section{$\underline{\text { Tell us about you: }}$}

The final set of questions ask for information about you so that we may better understand your travel choices.

46. What is your age?

47. What is your gender?

$\square$ female $\quad \square$ other (please specify) 

$\square$ male
$\square$ prefer not to answer

48. Would you describe yourself as... (Please check all that apply)

American Indian/Native American

Asian/Pacific Islander

Black/African American

$\square$ Hispanic/Latino
White/Caucasian

Other (please specify)

Prefer not to answer

49. What is your educational background? Please check highest level attained.
$\square$ Some grade / high school
Bachelor's degree
$\square$ High school / GED
$\square$ Graduate degree (MS, PhD, MBA etc.)
$\square$ Some college
$\square$ Professional degree (JD, MD, DDS etc.)
$\square$ Associate's degree
$\square$ Prefer not to answer

50. Do you have a driver's license or permit?

Yes $\square \quad$ No $\square$

51. Are you currently a student? Yes, full-time $\square \quad$ Yes, part-time

No

52. What is your current employment status?

$\square$ Full Time

$\square$ Homemaker / Unpaid Caregiver

$\square$ Part Time

$\square$ Not Employed / Retired

53. Do you live in a college dormitory or with roommates? Yes $\square \quad$ No $\square$

If you answered YES for question 53, answer questions about your household (questions 54 through 58) only for yourself.

54. Including yourself, how many people live in your household?

55. Including yourself, how many people in your household fall into each of the age groups listed below? persons under 6 years old persons $35-50$ persons 6-12 persons 51-65 persons $13-17$ persons 66-75 persons $18-26$ persons over the age of 75 persons $27-34$ $\square$ Prefer not to answer

56. Including yourself, how many people in your household hold a driver's license? people 
57. How many of the following does your household have?

bicycles

electric bicycles

mopeds or motorcycles

passenger cars, vans, SUVs, pickup trucks

motor homes, recreational vehicles, busses, or large trucks

58. Information about your income can help us to understand travel choices. Please choose the range that includes the approximate total annual income of your household before taxes.
$\square \$ 0-\$ 10,000$
$\square \$ 50,001-\$ 75,000$
$\$ 10,001-\$ 15,000$
$\square \$ 75,001-\$ 100,000$
$\square \$ 15,001-\$ 25,000$
$\square \$ 100,001-\$ 200,000$
$\square \$ 25,001-\$ 35,000$
$\square \$ 200,000+$
$\$ 35,001-\$ 50,000$
$\square$ Prefer not to answer

Questions 52 through 54 ask about geographic areas near your home. Information about your neighborhood environment can also be useful in understanding your travel behavior.

59. Zip code:

60. Name an intersection near your home by giving two street names

and

61. Name an intersection near your main work or school destination by giving two street names and

Do you have any additional comments? (Wish to expand upon any questions, give suggestions about the survey) 
Thank you for your participation!

If you are interested in learning the results from this survey, please provide your contact information:

Email: 